\title{
Application of Artificial Neural Network, Kriging, and Inverse Distance Weighting Models for Estimation of Scour Depth around Bridge Pier with Bed Sill
}

\author{
Homayoon Seyed Rahman, Keshavarzi Alireza*, Gazni Reza
}

Water Department, Shiraz University, Shiraz, Iran.

Email: keshavrz@shirazu.ac.ir

Received July 23 ${ }^{\text {rd }}$, 2010; revised August 23 ${ }^{\text {rd }}$, 2010; accepted August 25 ${ }^{\text {th }}, 2010$.

\begin{abstract}
This paper outlines the application of the multi-layer perceptron artificial neural network (ANN), ordinary kriging $(\mathrm{OK})$, and inverse distance weighting (IDW) models in the estimation of local scour depth around bridge piers. As part of this study, bridge piers were installed with bed sills at the bed of an experimental flume. Experimental tests were conducted under different flow conditions and varying distances between bridge pier and bed sill. The ANN, OK and IDW models were applied to the experimental data and it was shown that the artificial neural network model predicts local scour depth more accurately than the kriging and inverse distance weighting models. It was found that the ANN with two hidden layers was the optimum model to predict local scour depth. The results from the sixth test case showed that the ANN with one hidden layer and 17 hidden nodes was the best model to predict local scour depth. Whereas the results from the fifth test case found that the ANN with three hidden layers was the best model to predict local scour depth.
\end{abstract}

Keywords: Artificial Neural Network, Scour Depth, Ordinary Kriging, Inverse Distance Weighting, Bridge Piers, Bed Sill

\section{Introduction}

The accurate estimation of maximum scour depth around and downstream of bridge piers is critical and very important for design engineers. The prediction of scour depth around bridge piers has been the subject of many experimental studies, and has resulted in a number of prediction techniques being presented. Scour depth is a significant limiting factor when assigning the minimum depth of substructures, as it decreases the lateral capacity of the substructure.

To determine a technique for predicting scour depth for different pier positions, comprehensive experimental tests have been conducted. In the past, a number of research studies had been conducted to determine techniques for the estimation of local scour around bridge piers and their abutments. These have been reported in literature. Of these studies, the first extensive experi-

*Present Address: School of Civil \& Environmental Engineering, UTS, Sydney, Australia. mental work on bridge pier scour was conducted and reported by Chabert and Engeldinger (1956) which is cited by Jeng et al. [1]. A study was also conducted by Blodgett (1978), again is cited by Jeng et al. [1], to report the cause of failure of 383 bridges. It was reported that most failures were caused by catastrophic floods. This study also found that the incorrect prediction of local scour depth during engineering design lead to enlarged local and contraction scour. Yankielun and Zabilansky [2] pointed out that this serious problem costs millions of dollars worth of damage, leaving foundations of bridge piers and bridge abutments insecure. Johnson [3] compared some of proposed prediction methods with the available field data, and concluded that more research is still required to accurately determine local scour.

To overcome this complicated problem, the artificial neural network (ANN) was found to be useful as a comprehensive function approximator, especially when the relationship between dependent and independent variables is inadequately understood [1]. Trent et al. [4,5] 
applied ANN to estimate local pier scour and sediment transport in open channels. Choi and Cheong [6] estimated local scour around bridge piers using ANN and concluded that the ANN can successfully predict the depth of scour over a wider range of conditions with a greater accuracy than existing empirical formulae.

Butcher [7] pointed out that the kriging methods of geostatistical analysis provide valuable techniques for the analysis of sediment contamination problems, including interpolation of concentration maps from point data and the estimation of global mean concentrations. Biglari and Sturm [8] pointed out that bridge failure due to local scour around piers and abutments has motivated many examinations into scour prediction, as well as reliable design methods. Liriano and Day [9] compared current prediction equations for culvert outlets with results obtained from two ANN models. They concluded that the ANN model can be used to predict local scour in laboratory and in the field better than other empirical relationships that are currently in use.

Kambekar and Deo [10] analyzed scour data using different neural network models that were developed to predict scour depth. They found that the neural network provides a better alternative to statistical curve fitting. Jeng et al. [1], Bateni et al. [11] and Lee et al. [12] applied neural networks to predict scour depths around bridge piers. Bateni et al. [13] used Bayesian neural networks for the prediction of equilibrium and time- dependent scour depth around bridge piers. They showed that the new models estimate equilibrium and time-dependent scour depth more accurately than the existing expressions.

The results of training and testing ANN obtained from these models have been analyzed and an accurate model to predict local scour depth around a bridge pier in a river environment has been produced. (see Figures 1 and 2) These results contribute to the understanding of local scour and provide engineers with a way of determining scour depth for a variety of pier situations.

In most previous studies, scouring was studied around bridge piers installed without the presence of a bed sill. This paper presents the experimental data used to investigate bridge scour around a pier installed upstream of a bed sill and explores the use of artificial neural networks, kriging and inverse distance weighting models to estimate the scour depth around a bridge pier.

\section{Experiment Setup and Procedure}

A dimensional analysis was conducted to find the most important parameters for bed scouring around a curved

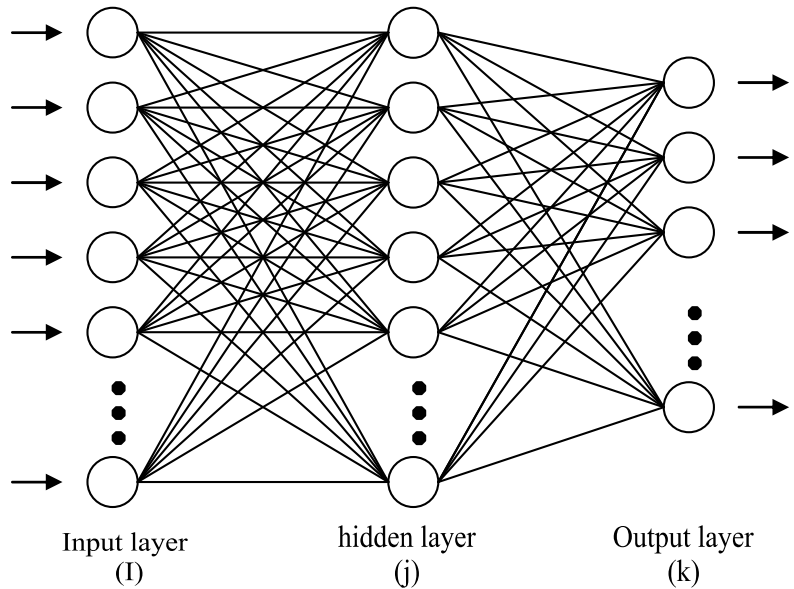

Figure 1. Conceptual diagram of a feed forward network with one hidden layer.

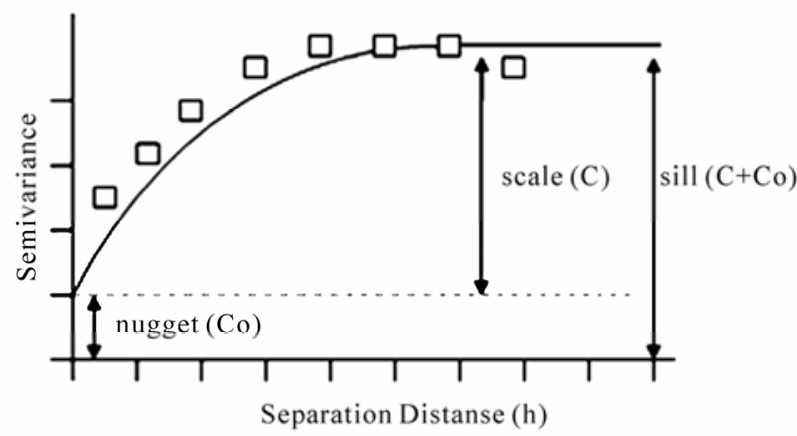

Figure 2. Variogram parameters.

bed sill installed downstream of a bridge pier. The most effective parameters were found to be;

$$
Y_{S}=f\left(g, v, \rho_{w}, \rho_{s}, q, W, d_{50}, r, D\right)
$$

in which $Y_{s}$ is the scouring depth, $g$ is the acceleration of gravity, $\rho_{w}$ is the flow density, $\rho_{s}$ is the particle density, $q$ is the flow discharge per unit width, $d_{50}$ is the median particle diameter, $W$ is the width of the channel, $r$ is the arch distance of the circular sill and D is sill diameter. In this experimental study the $r / W$ and $D / W$ are investigated only during the laboratory experiments.

The laboratory experiments were carried out with 50 $\mathrm{mm}$ diameter circular piers installed at different distances from bed sill. The sill height was $12 \mathrm{~cm}$ and it was installed in a $15 \mathrm{~m}$ long, $0.5 \mathrm{~m}$ wide, $0.5 \mathrm{~m}$ deep experimental flume in the Hydraulic Laboratory College of Agriculture, Shiraz University. The scour depth and flow depth were measured using a sandy surface meter. The experiment setup and pier installation are shown in Figure 3.

The length and width of the scour were measured after each experiment. The longitudinal profile and maximum 

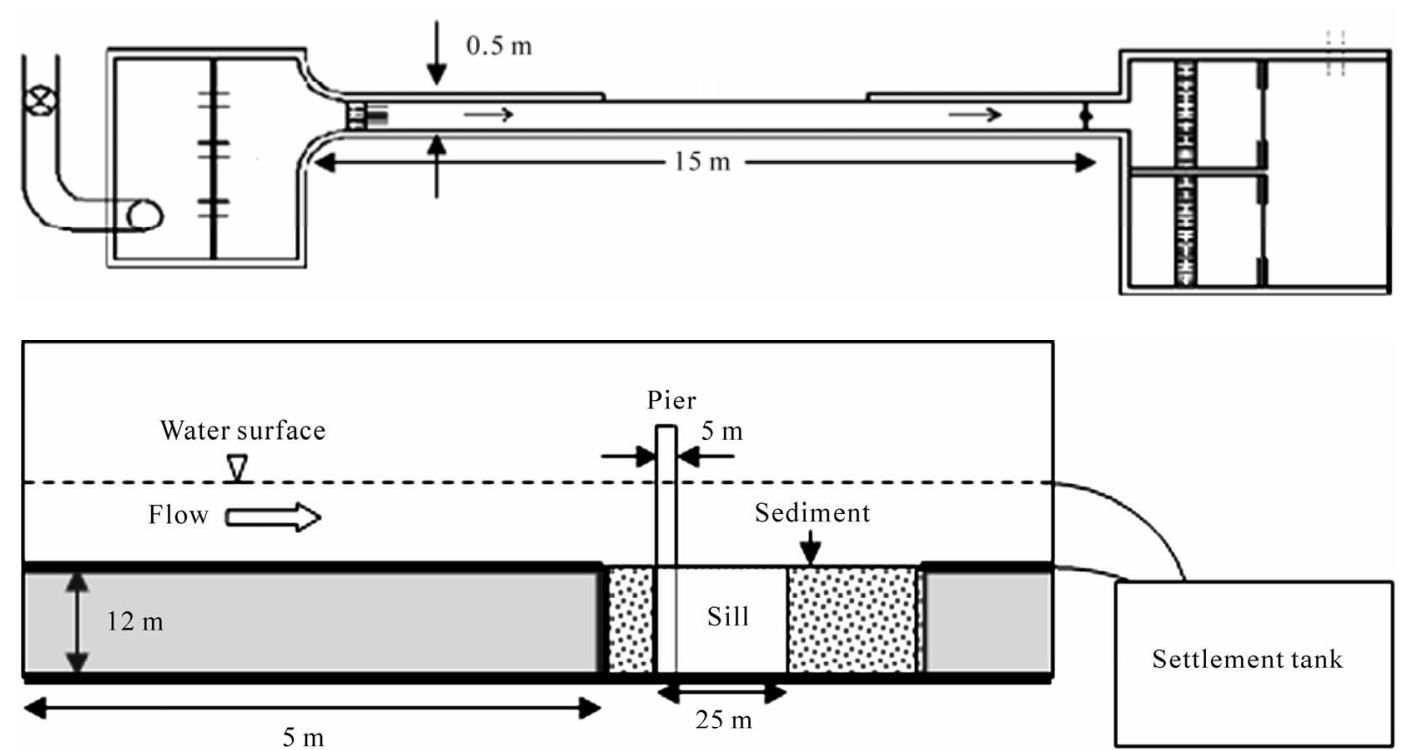

Figure 3. Experimental setup and pier installation.

depth of the scour were measured during the experiments. The scour measured on the side and at the rear of the pier were approximately the same, whilst the scour measured at the nose of the pier was less than the back scour.

A false bottom was installed in the flume to create a recess for the sediment bed. The recess was $2.5 \mathrm{~m}$ long, $0.5 \mathrm{~m}$ wide and $0.12 \mathrm{~m}$ deep and filled with non-cohesive sediment with $D_{50}$ equal to $0.5 \mathrm{~mm}$ diameter and standard deviation equal to $1.23 \mathrm{~mm}$. The pier was installed firstly by preparing an undersized pilot hole, pushing the pier in, and then trimming off the remaining sediment. Water entered the flume smoothly from an inlet reservoir, and a sediment trap was used at the downstream end of the test reach. Downstream of the trap, water passed over a tailgate into a sump. Water depth in the in-floor flume was controlled by a tail gate located at the downstream end of the test section. All the experiments were conducted under steady flow conditions. The flow discharge was measured by a 90 degree V-Notch and an electromagnetic flow meter.

Experimental test cases were conducted in eight different bed sill models (Figure 4). Table 1 explains the flow condition of the experimental tests.

\section{Results and Discussions}

\subsection{The ANN, OK and IDW Estimations for Scour around Piers}

The whole data set, consisting of 2754 data points, was composed of eight different conditions. Each condition was divided into two parts randomly: a training set con- sisting of $80 \%$ of the data points and a validation or testing set consisting of $20 \%$ of the data points.

In this study, two types of ANN models were developed: 1) single hidden-layer ANN model consisting of only one hidden layer, and 2) multiple hidden-layer ANN model consisting of two and three hidden layers. The task of identifying the number of neurons in the input and output layers is usually simple, as it is dictated by the input and output variables considered to model the physical process.

As previously mentioned, the number of neurons in the hidden layer(s) can be determined through the use of trial and error procedure [1]. The optimal architecture was determined by varying the number of hidden neurons (from 1 to 20), and then the best structure was selected. The training of the ANN models was stopped when either the acceptable level of error was achieved or when the number of iterations exceeded a prescribed maximum of 2500. The learning rate of 0.05 was also used.

ANN was implemented using the MATLAB software package (MATLAB version 7.2 with neural network toolboxes) [14].

The performance of ANN, OK and IDW configurations were assessed based on calculating the mean absolute error (MAE), and the root mean square error (RMSE). (see Table 2).

The coefficient of determination, $R^{2}$ of linear regression line, between the predicted values from each method and the desired output were also used as a measure of performance. The three statistical parameters used to compare the performance of the various method con- 


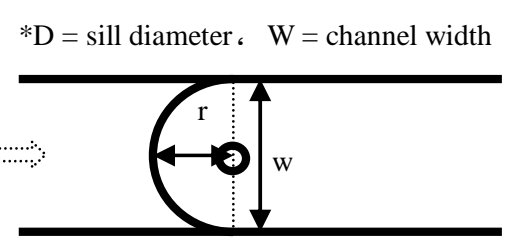

a) Test case 1 :

$$
\mathrm{D}=\mathrm{W}
$$

$\mathrm{r}=25 \mathrm{~cm}, \mathrm{w}=50 \mathrm{~cm}$

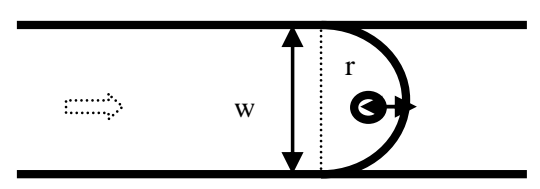

d) Test case 4:

$$
\mathrm{D}=\mathrm{W}
$$

$\mathrm{r}=5 \mathrm{~cm}, \mathrm{w}=50 \mathrm{~cm}$

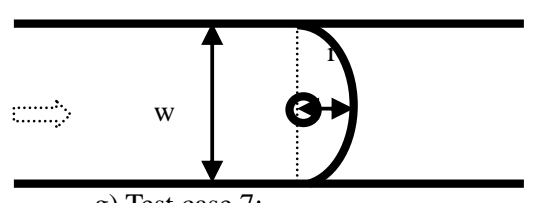

g) Test case 7:

$\mathrm{D}=1.2 \mathrm{~W}$

$\mathrm{r}=15 \mathrm{~cm}, \mathrm{w}=50 \mathrm{~cm}$

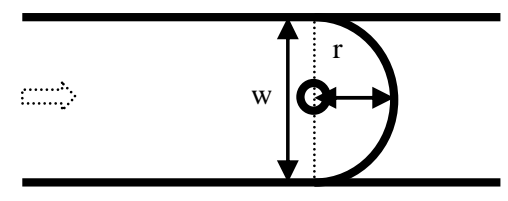

b) Test case 2:

$$
\mathrm{D}=\mathrm{W}
$$

$\mathrm{r}=25 \mathrm{~cm}, \mathrm{w}=50 \mathrm{~cm}$

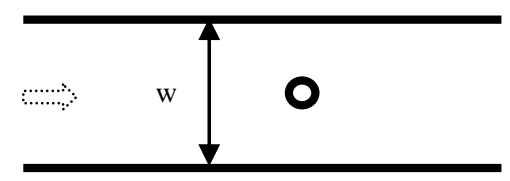

e) Test case 5:

$$
\text { No sill }
$$$$
\mathrm{w}=50 \mathrm{~cm}
$$

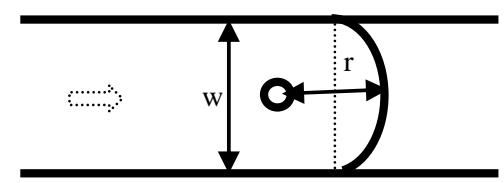

h) Test case 8:

$$
\mathrm{D}=1.2 \mathrm{~W}
$$

$$
\mathrm{r}=25 \mathrm{~cm}, \mathrm{w}=50 \mathrm{~cm}
$$

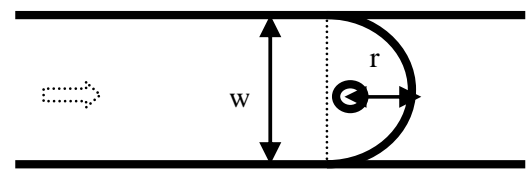

c) Test case 3:

$$
\mathrm{D}=\mathrm{W}
$$

$\mathrm{r}=15 \mathrm{~cm}, \mathrm{w}=50 \mathrm{~cm}$

\begin{tabular}{|c|c|c|c|c|c|c|c|}
\hline Test Case & $\mathrm{D} / \mathrm{W}^{*}$ & Discharge (lit/sec) & Head water (cm) & sill radius $(\mathrm{cm})$ & Velocity (m/s) & $\mathrm{F}_{\mathrm{r}}$ & Pier diameter (cm) \\
\hline 1 & 1 & 13.3 & 9 & 25 & 0.2955 & 0.31 & 5 \\
\hline 2 & 1 & 12.64 & 7.9 & 25 & 0.32 & 0.363 & 5 \\
\hline 3 & 1 & 10 & 8.3 & 25 & 0.241 & 0.267 & 5 \\
\hline 4 & 1 & 11 & 9.2 & 25 & 0.239 & 0.252 & 5 \\
\hline 5 & ---- & 9.5 & 7.8 & ---- & 0.244 & 0.279 & 5 \\
\hline 6 & 1.2 & 9.5 & 7.6 & 30 & 0.25 & 0.289 & 5 \\
\hline 7 & 1.2 & 8.4 & 7.2 & 30 & 0.233 & 0.277 & 5 \\
\hline 8 & 1.2 & 7 & 5.2 & 30 & 0.269 & 0.377 & 5 \\
\hline
\end{tabular}

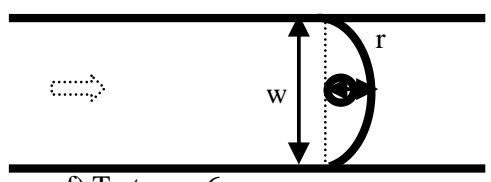

f) Test case 6 :

$$
\mathrm{D}=1.2 \mathrm{~W}
$$

$\mathrm{r}=5 \mathrm{~cm}, \mathrm{w}=50 \mathrm{~cm}$

Figure 4. Schematic configuration of eight bed sill models used in this study.

Table 1. Hydraulic condition and geometric parameters of the experimental tests.

figurations are:

$$
\begin{aligned}
M A E & =\frac{1}{N} \sum_{i=1}^{N}\left|O_{i}-t_{i}\right|, \\
R M S E & =\sqrt{\frac{\sum_{i=1}^{N}\left(O_{i}-t_{i}\right)^{2}}{N},}
\end{aligned}
$$

$$
R^{2}=1-\frac{\sum_{i=1}^{N}\left(O_{i}-t_{i}\right)^{2}}{\sum_{i=1}^{N}\left(O_{i}-\bar{O}_{i}\right)^{2}}
$$

where: $O_{i}$ and $t_{i}$ are observed and predicted for the $i$ th output, and $\bar{O}_{i}$ is the average of predicted, and $\mathrm{N}$ is the total number of events considered. 
Table 2. Performance of all test cases.

\begin{tabular}{|c|c|c|c|c|c|c|c|}
\hline \multirow{2}{*}{ Test Cases } & \multirow{2}{*}{ Methods } & \multicolumn{3}{|c|}{ Validation } & \multicolumn{3}{|c|}{ Training } \\
\hline & & MAE & RMSE & $\mathrm{R}^{\wedge} 2$ & MAE & RMSE & $\mathrm{R}^{\wedge} 2$ \\
\hline \multirow{3}{*}{ First test case } & ANN & 1.93 & 5.48 & 0.989 & 0.46 & 2.14 & 0.998 \\
\hline & OK & 2.99 & 6.83 & 0.954 & 2.73 & 5.19 & 0.957 \\
\hline & IDW & 4.31 & 8.19 & 0.912 & 3.74 & 6.08 & 0.913 \\
\hline \multirow{3}{*}{ Second test case } & ANN & 4.92 & 4.39 & 0.931 & 1.71 & 2.85 & 0.993 \\
\hline & OK & 4.45 & 4.47 & 0.927 & 5.47 & 5.09 & 0.861 \\
\hline & IDW & 6.90 & 5.57 & 0.918 & 8.37 & 6.30 & 0.831 \\
\hline \multirow{3}{*}{ Third test case } & ANN & 2.62 & 3.40 & 0.970 & 1.64 & 2.52 & 0.992 \\
\hline & OK & 2.99 & 3.64 & 0.945 & 5.42 & 4.57 & 0.844 \\
\hline & IDW & 3.91 & 4.16 & 0.937 & 6.18 & 4.89 & 0.839 \\
\hline \multirow{3}{*}{ Fourth test case } & ANN & 4.36 & 5.10 & 0.951 & 3.41 & 4.21 & 0.971 \\
\hline & $\mathrm{OK}$ & 3.95 & 4.91 & 0.916 & 3.27 & 4.12 & 0.944 \\
\hline & IDW & 4.64 & 5.32 & 0.909 & 3.99 & 4.56 & 0.941 \\
\hline \multirow{3}{*}{ Fifth test case } & ANN & 0.78 & 4.38 & 0.997 & 0.71 & 3.65 & 0.998 \\
\hline & OK & 1.04 & 5.05 & 0.995 & 1.26 & 4.88 & 0.994 \\
\hline & IDW & 1.28 & 5.61 & 0.991 & 1.43 & 5.19 & 0.992 \\
\hline \multirow{3}{*}{ Sixth test case } & ANN & 2.37 & 3.31 & 0.931 & 2.58 & 1.92 & 0.980 \\
\hline & OK & 4.32 & 4.47 & 0.930 & 11.79 & 4.11 & 0.609 \\
\hline & IDW & 4.99 & 4.80 & 0.918 & 11.80 & 4.11 & 0.609 \\
\hline \multirow{3}{*}{ Seventh test case } & ANN & 2.35 & 6.78 & 0.937 & 1.59 & 5.16 & 0.980 \\
\hline & OK & 3.65 & 8.46 & 0.897 & 3.78 & 7.96 & 0.934 \\
\hline & IDW & 3.92 & 8.76 & 0.878 & 2.99 & 7.08 & 0.945 \\
\hline \multirow{3}{*}{ Eighth test case } & ANN & 1.75 & 3.53 & 0.987 & 0.90 & 2.63 & 0.998 \\
\hline & OK & 2.99 & 4.62 & 0.963 & 3.22 & 4.98 & 0.965 \\
\hline & IDW & 3.07 & 4.68 & 0.961 & 2.60 & 4.47 & 0.969 \\
\hline
\end{tabular}

Cross-validation analysis was used to evaluate effective parameters for OK and IDW interpolations and to compare the different estimation techniques to determine the best approach for accurate prediction data. In cross-validation, each measured point in a spatial domain is individually removed from the domain and its value is estimated by kriging and compared to the actual value as though it were never there (Gamma Design Software [15]).

\subsection{First Test Case}

In first test case, the tip of the sill was set in the flow 
direction (in the shape of a convex) and a space of $25 \mathrm{~cm}$ was set between the sill and bridge pier. The diameter of the sill is equal to the flume width.

In ANN prediction, optimal architecture is determined by varying the number of hidden neurons (from 1 to 20), and the best structure is selected. It was found that the most accurate results involved use of the feed forward back propagation with two hidden layers and an architecture of configuration: 2-7-4-1.

To evaluate the performance of the ANN, OK and IDW, observed local scour depth values are plotted against the predicted values. Figure 5 illustrates the results with the performance indices between predicted and observed data for the training and testing data sets, respectively.

Figures 5(c-f) also exhibit that kriging has a lower training error compared with IDW, and its validation error becomes lower than IDW. In other words, kriging validation results have a lower scatter than IDW. As it can be seen from Figure 5(a-b), ANN has performed well in predicting the local scour depth.

Comparing ANN results with those of OK and IDW it is found that ANN has the lowest training error and validation error, then kriging and IDW. Also interpolated local scour maps (Figure 6) show that the interpolated map of the ANN model is more similar to the interpolated map of the observation map as compared with the interpolated map of kriging and IDW.

\subsection{Second Test Case}

In the second test case, the bed sill was set in the flow direction (in the shape of a concave) and spaces of $25 \mathrm{~cm}$ were set between the bridge pier and bed sill. Figure 7 illustrates the results with the performance indices between predicted and observed data for the training and testing data sets, respectively.

When the methods were compared, the training accuracy was significant. It is observed that all models perform with poor accuracy in comparison with results of the first data set. Comparison between these three validations of evaluating scour depth in all runs for ANN, OK and IDW revealed that the difference in accuracy between those was not significant. Also the accuracy of training in OK and IDW was less than the validation. It is shown that these methods are not reliable in this condition because it cannot predict the training data well. In this condition, the ANN model performed well and the IDW had the lowest accuracy. The interpolated maps are demonstrated in Figure 8.

\subsection{Third Test Case}

In a similar manner, the third condition data was used to predict local scour depth with ANN, OK and IDW. In this third test case, similar to second test, the bed sill was set in the flow direction but the distance between the bridge pier and bed sill was set to $15 \mathrm{~cm}$.

Figure 9 shows the results with the performance indices between predicted and observed data for the training and testing data sets, respectively. Again, the ANN model performs well in training and validation. The accuracy of prediction was not considerably different between OK and IDW and as it is shown in Figure 10. The interpolated map of observation data, ANN, OK and IDW for the third test case is shown in Figure 10.

Accuracy of training was more than validation in the ANN prediction, whereas in the two other mentioned methods, correctness of training was less than the validation. In other words, the results of the OK and IDW were not as precise as for ANN. The accuracy in training of ANN was more reliable when compared with $\mathrm{OK}$ and IDW methods.

\subsection{Fourth Test Case}

The fourth test case was similar to second test, but the distance between bridge pier and bed sill was set to $5 \mathrm{~cm}$. From ANN prediction, the best structure was found to be a configuration of 2-4-4-1.

Figure 11 shows the results with the performance indices between predicted and observed data for the training and testing data sets, respectively.

The three interpolated maps of the aforementioned methods are very similar (Figure 12) and comparison between these three training and validations for evaluating scour depth in all runs for ANN, OK and IDW revealed that the difference in accuracy between them was not significant.

\subsection{Fifth Test Case}

In the fifth test case the bridge pier was set separately in the flume. From ANN estimates, unlike the previous four conditions, the best result was obtained for a 2-4-4-4-1 structure.

The comparison between these three training and validations for evaluating scour depth in all runs for ANN, OK and IDW revealed that the difference in accuracy between these was not significant (Figure 13). It was found that the ANN accuracy was better than other methods.

This test was similar to the fourth test where the three interpolated maps of the methods were very similar to interpolated map of observed data (Figure 14).

\subsection{Sixth Test Case}

This experiment was similar to the second test case, 


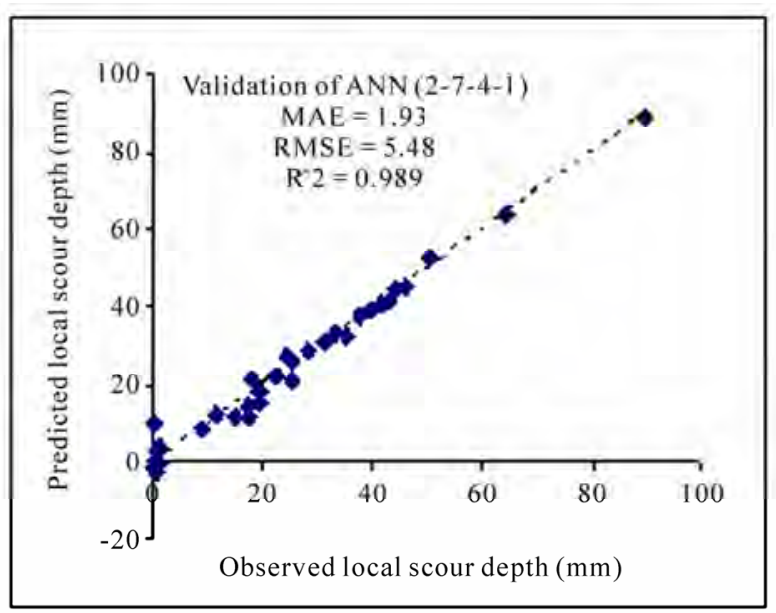

(a)

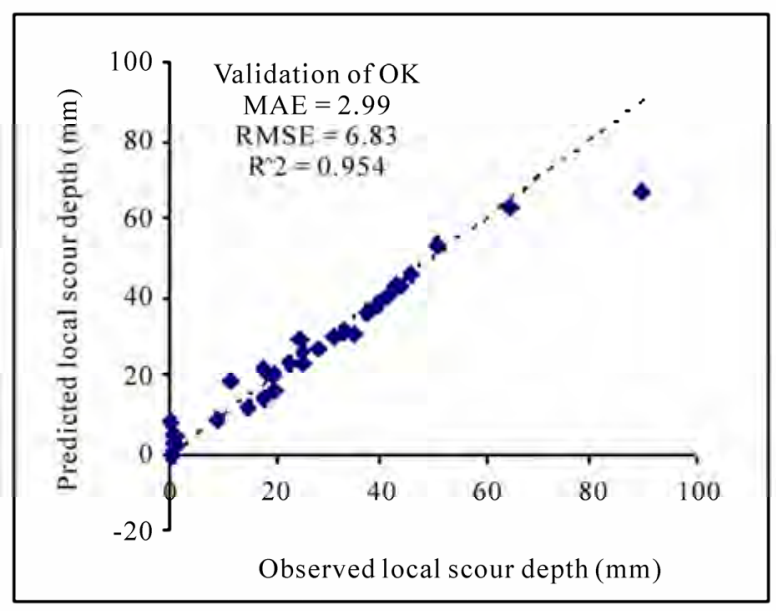

(c)

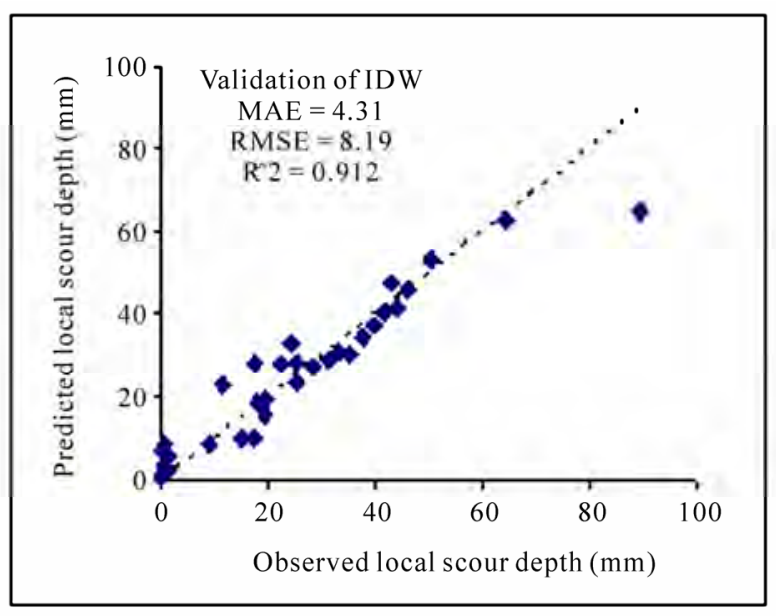

(e)

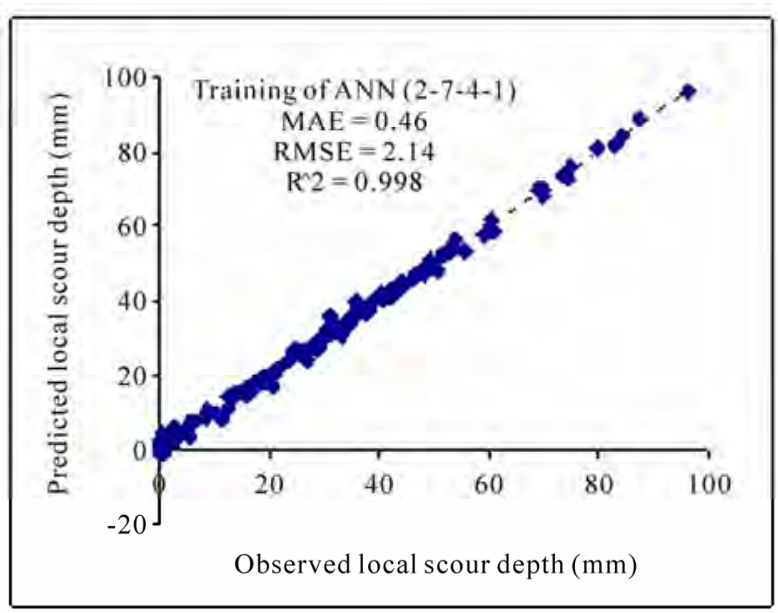

(b)

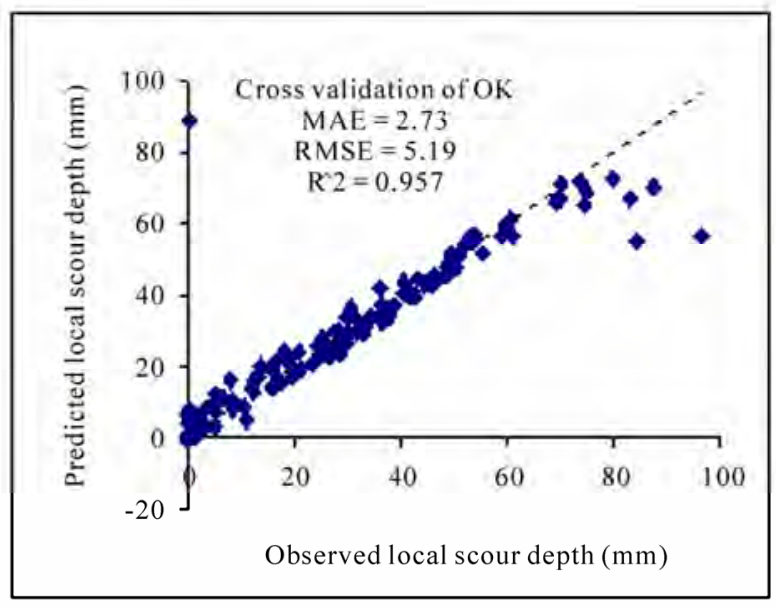

(d)

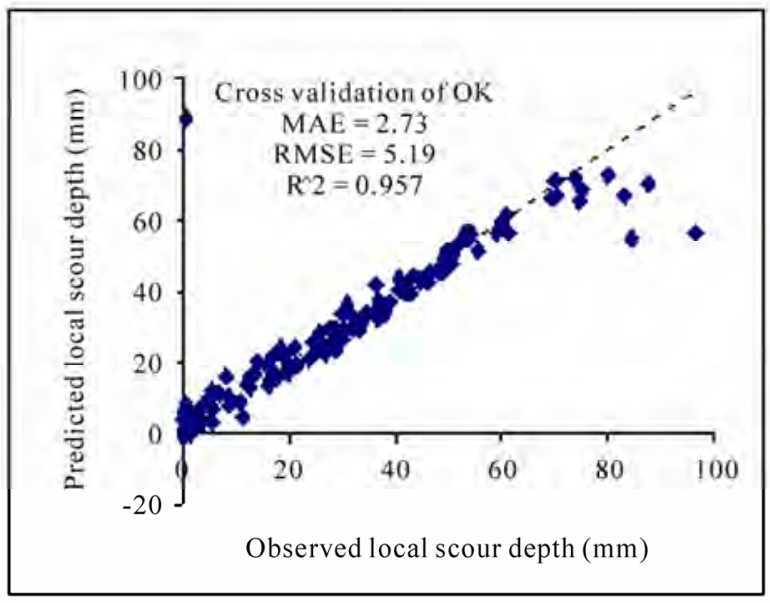

(f)

Figure 5. Performance of ANN, OK and IDW for the first test case: (a) ANN Validation; (b) ANN Training; (c) OK Validation; (d) OK Cross Validation; (e) IDW Validation; (f) IDW Cross Validation. 

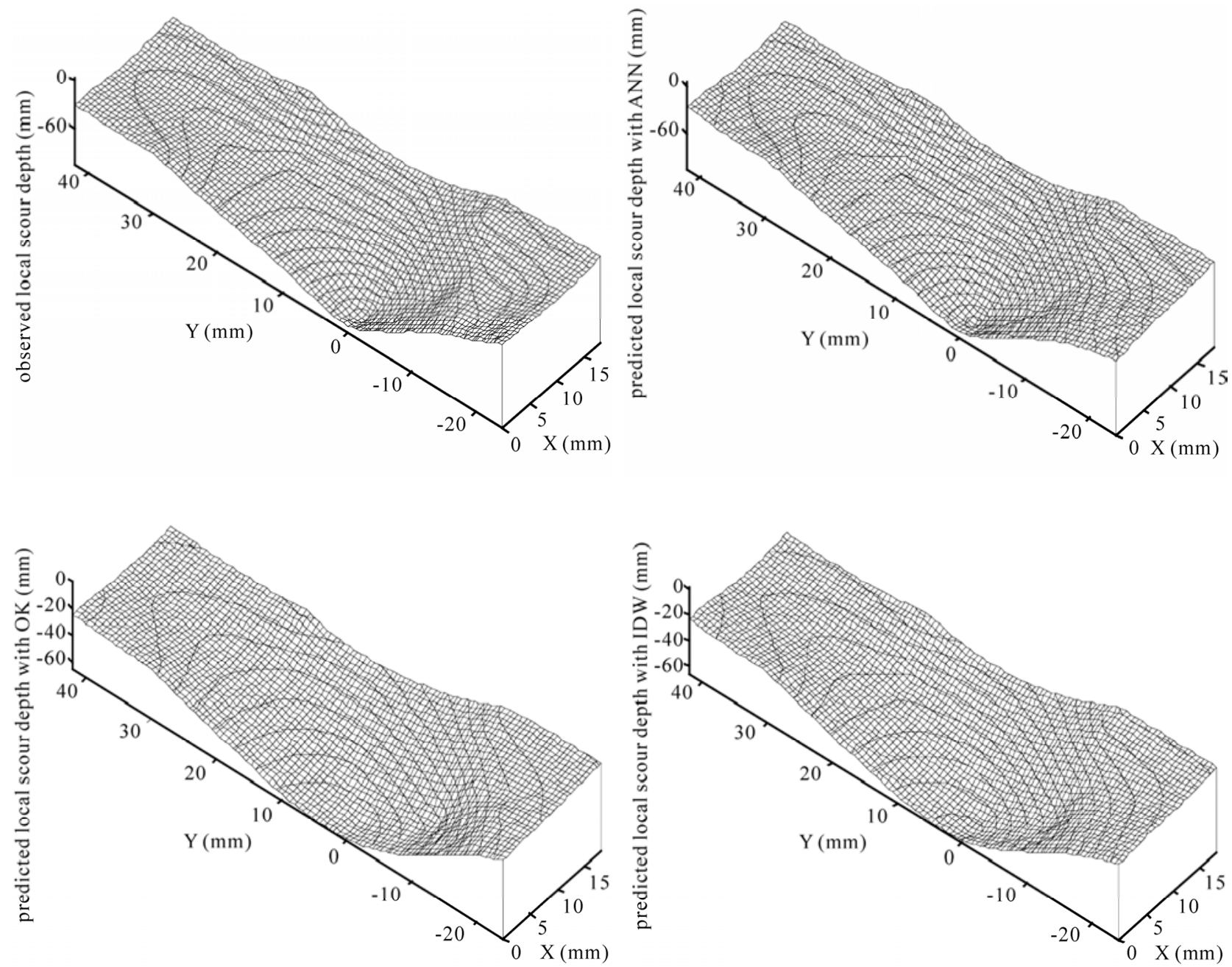

Figure 6. Interpolated maps of observed data, ANN, OK and IDW test for first test case.

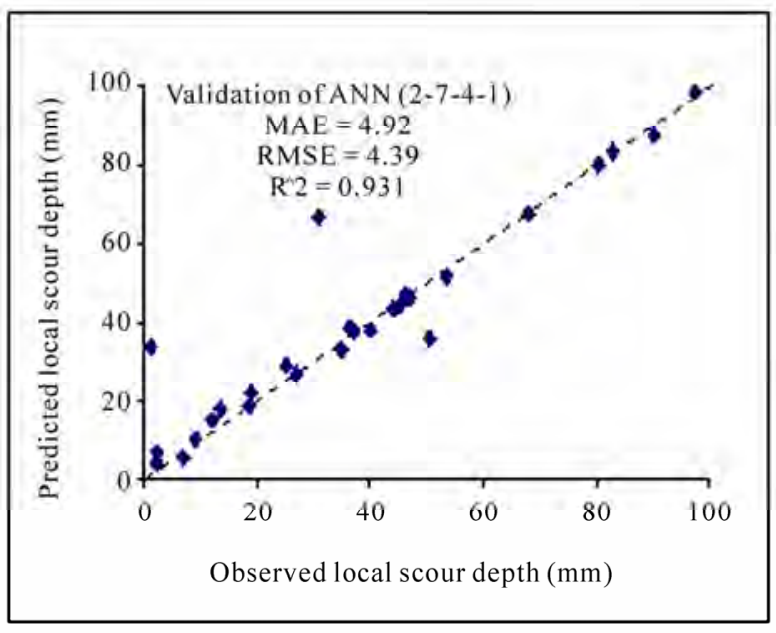

(a)

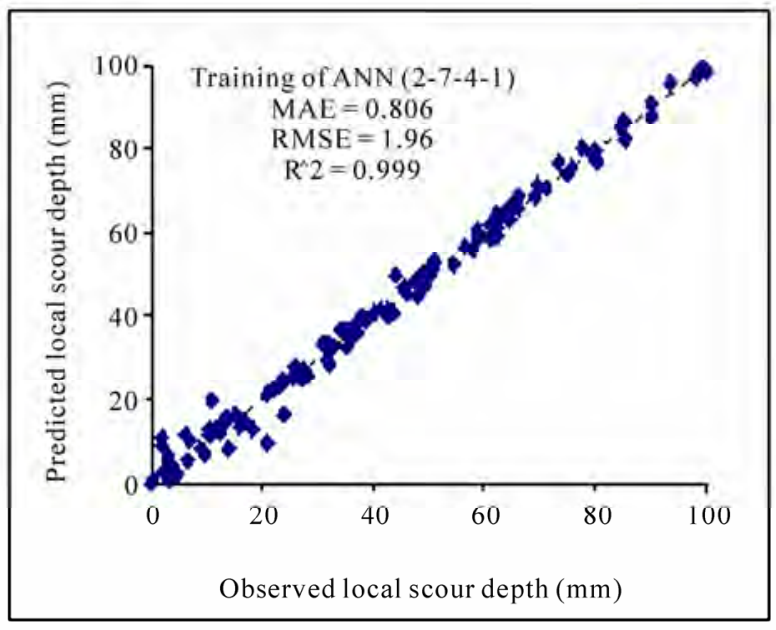

(b) 


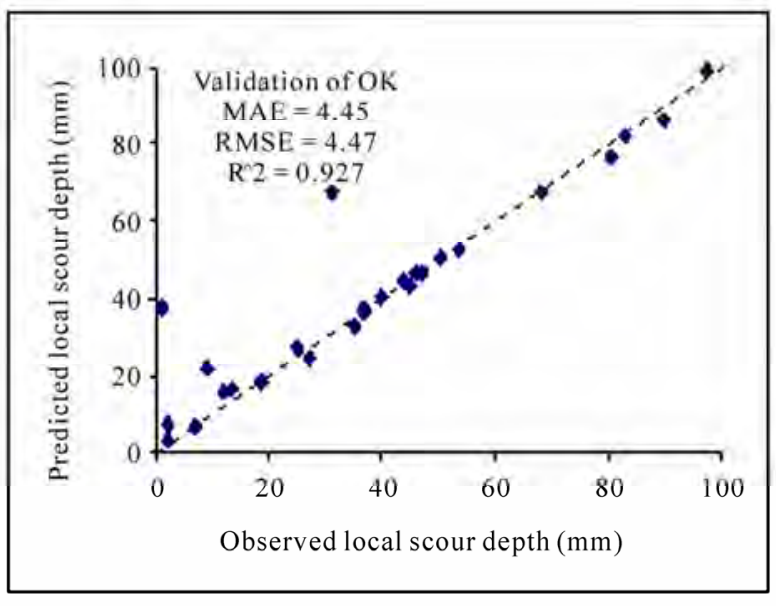

(c)

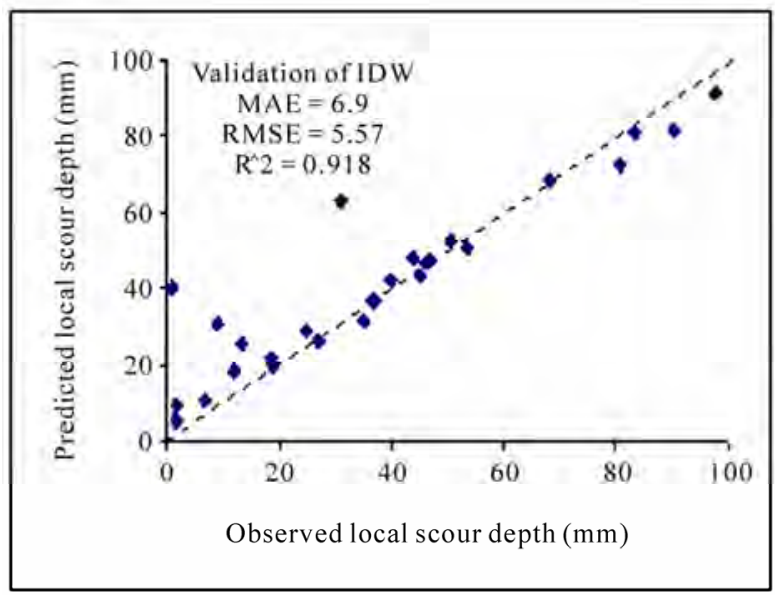

(e)

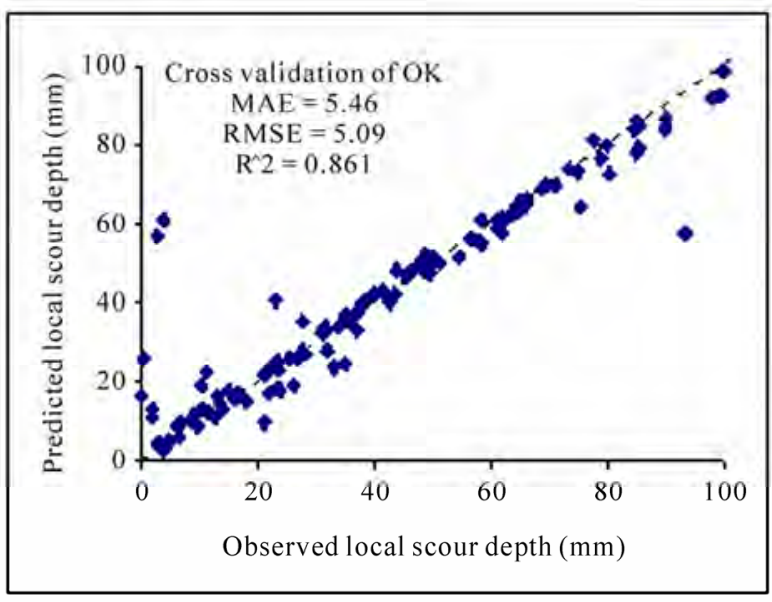

(d)

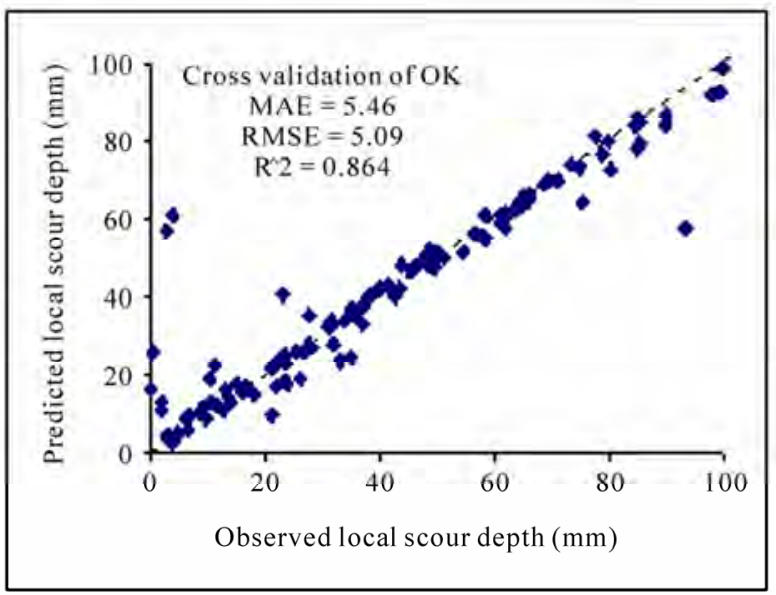

(f)

Performance of ANN of first test case (convex type); (a) testing, (b) training

Figure 7. Performance of ANN, OK and IDW for the 2nd test case: (a) ANN Validation; (b) ANN Training; (c) OK Validation; (d) OK Cross Validation; (e) IDW Validation; (f) IDW Cross Validation.
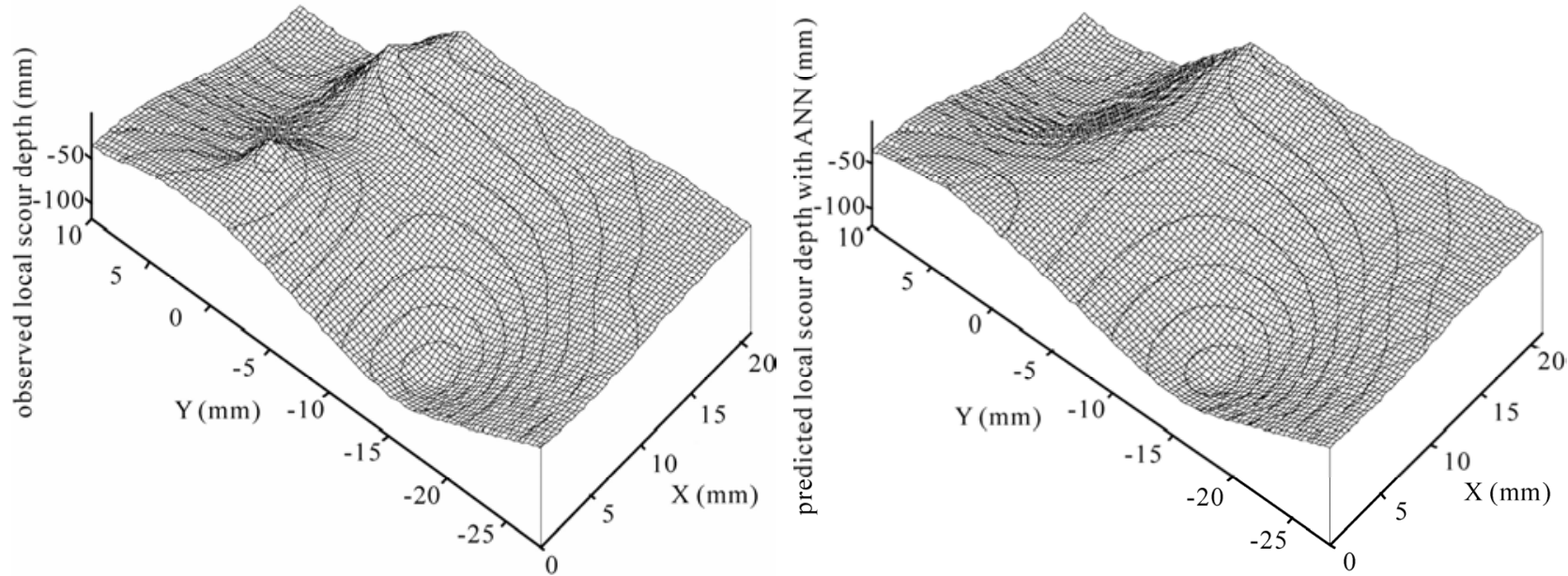

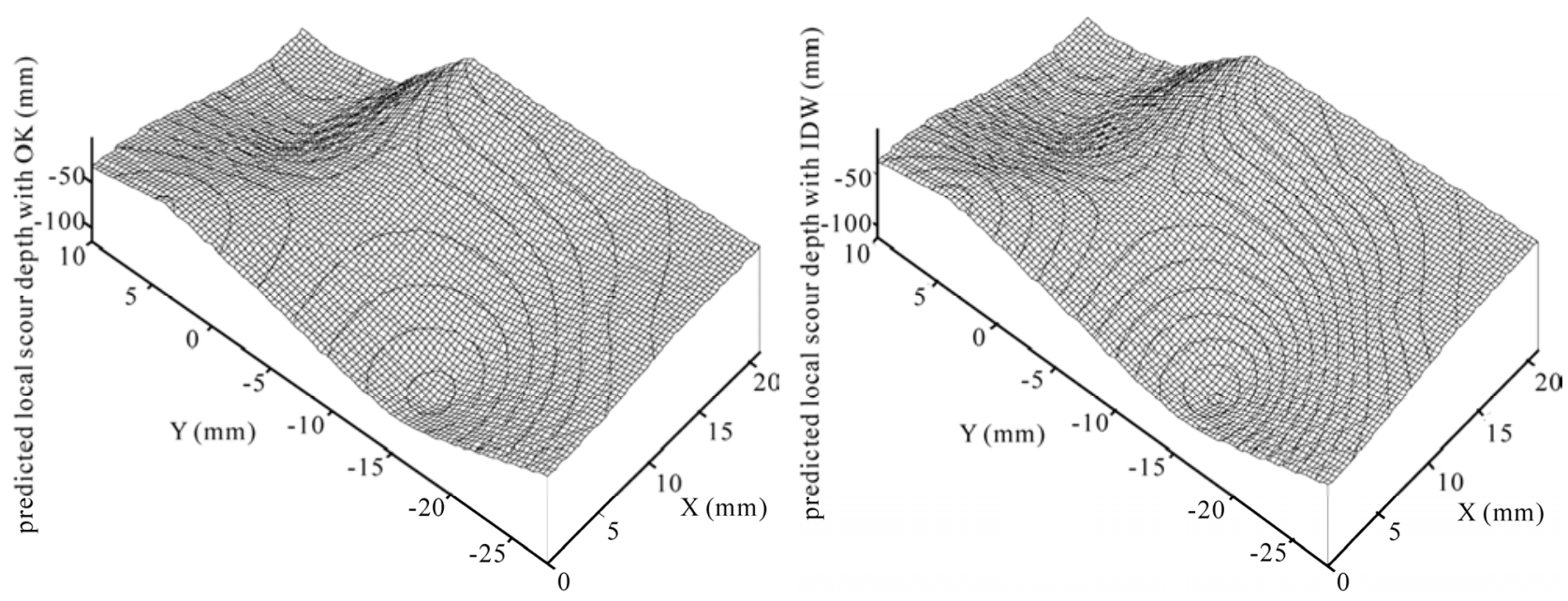

Figure 8. Interpolated maps of observed data, ANN, OK and IDW test for second test case.

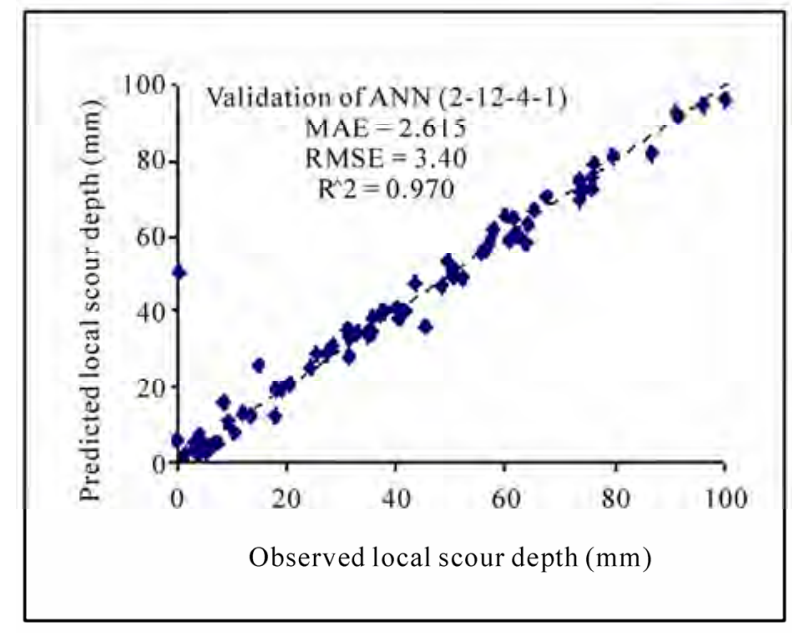

(a)

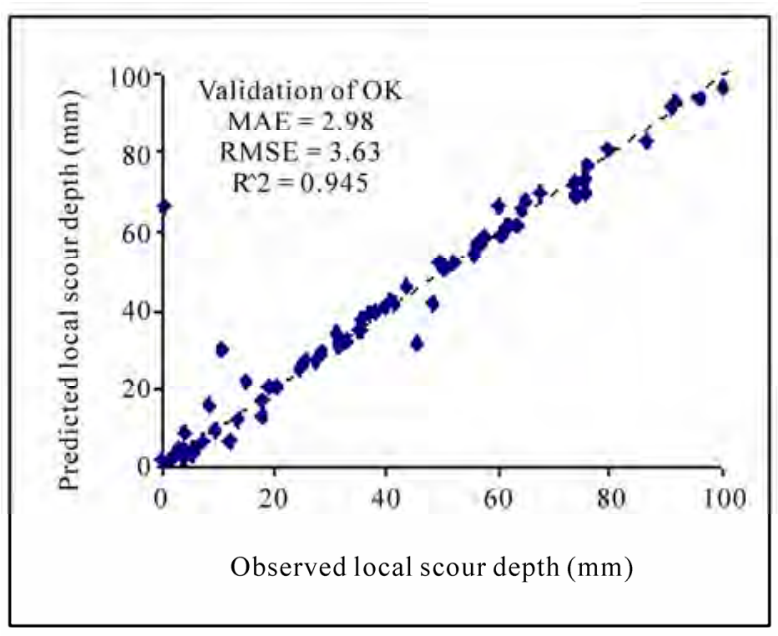

(c)

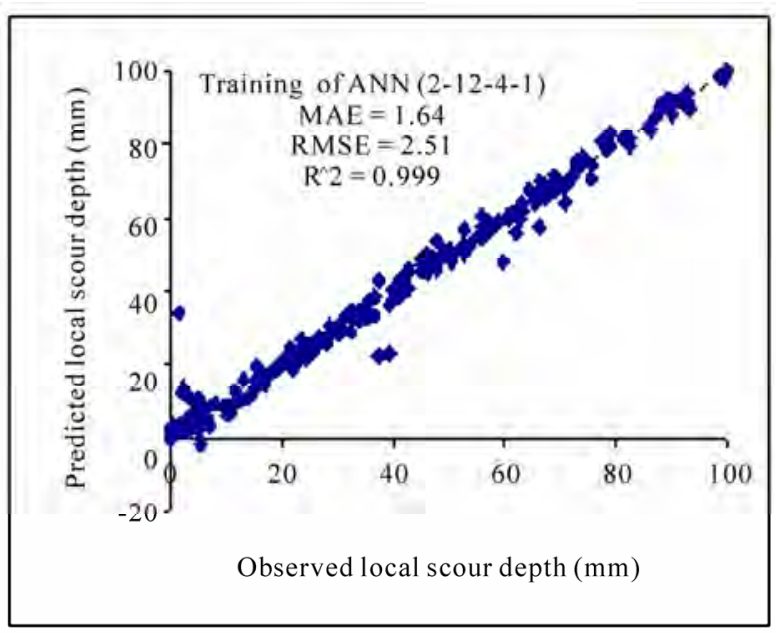

(b)

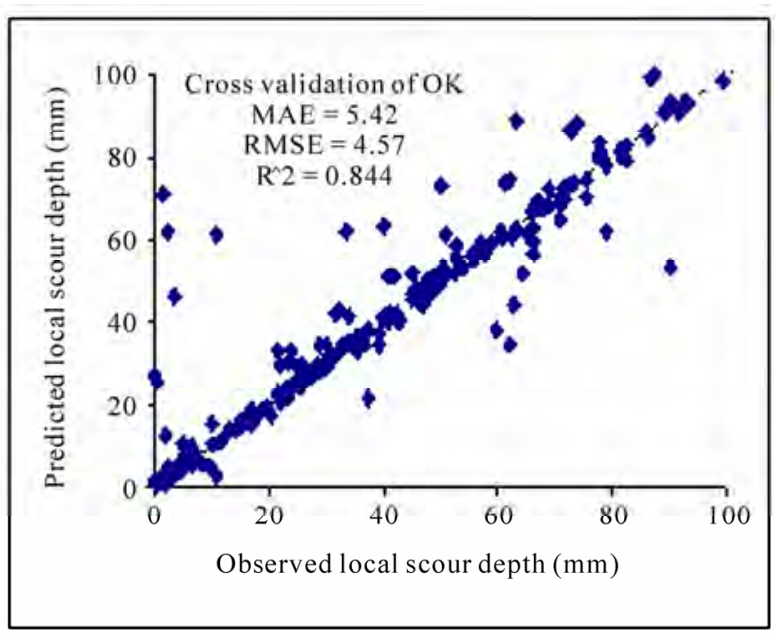

(d) 


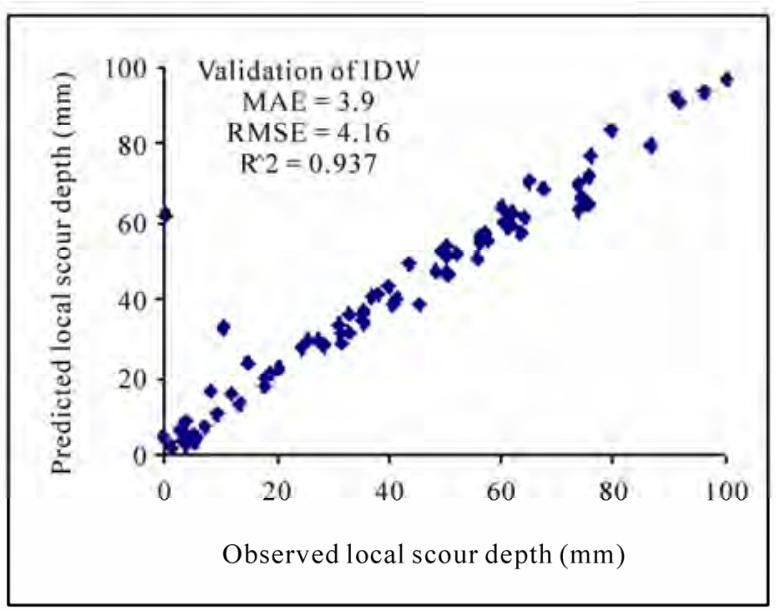

(e)

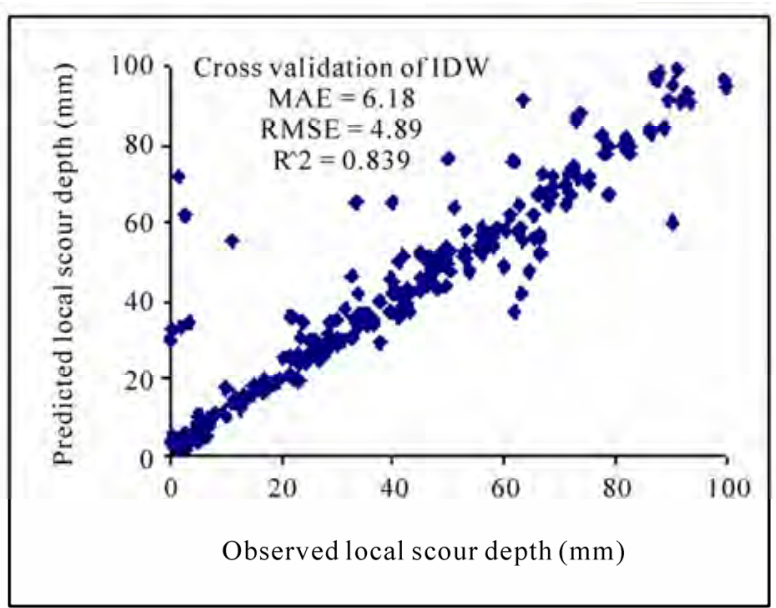

(f)

Figure 9. Performance of ANN, OK and IDW for the third test case: (a) ANN Validation; (b) ANN Training; (c) OK Validation; (d) OK Cross Validation; (e) IDW Validation; (f) IDW Cross Validation.
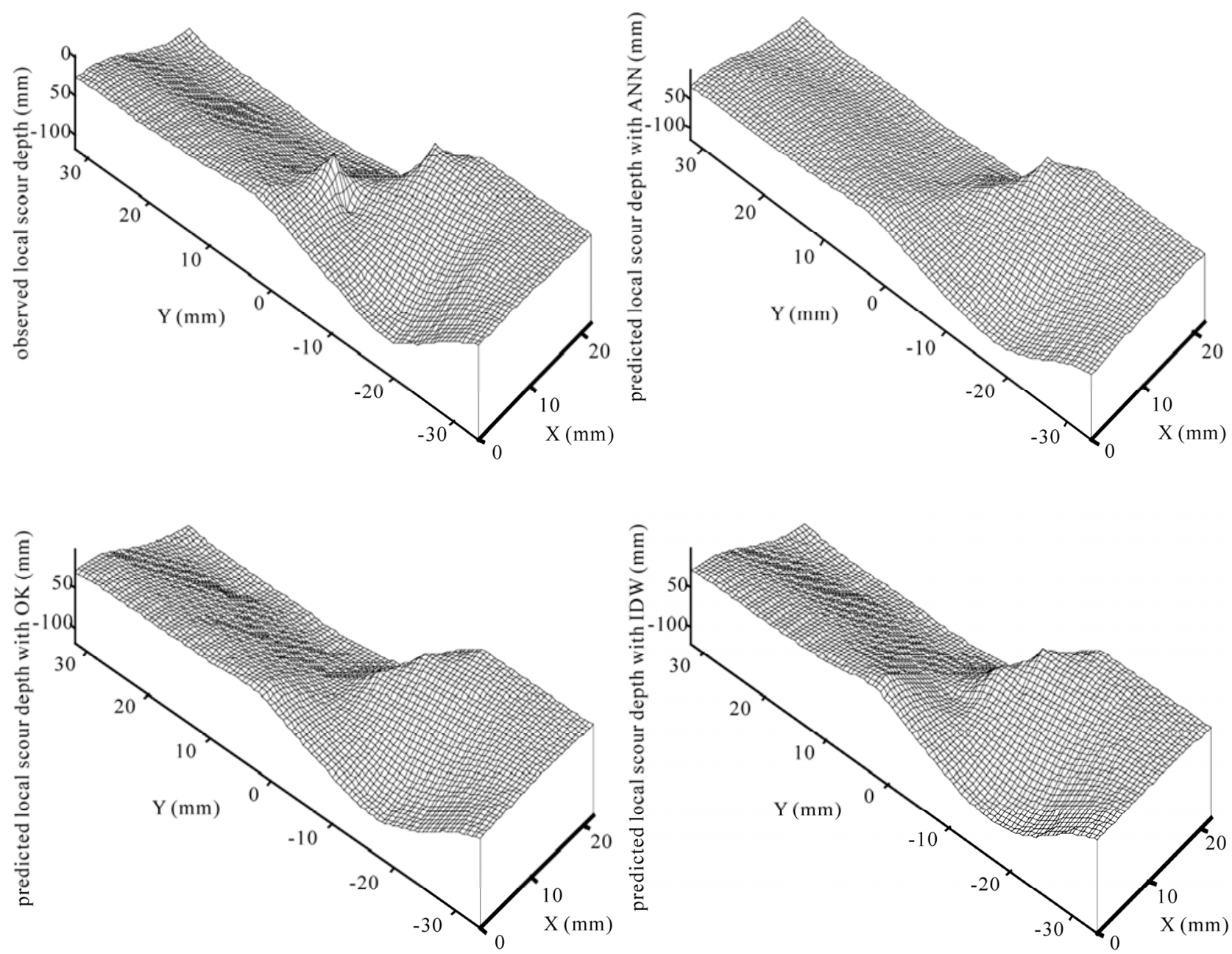

Figure 10. Interpolated maps of observed data, ANN, OK and IDW test for third test case. 


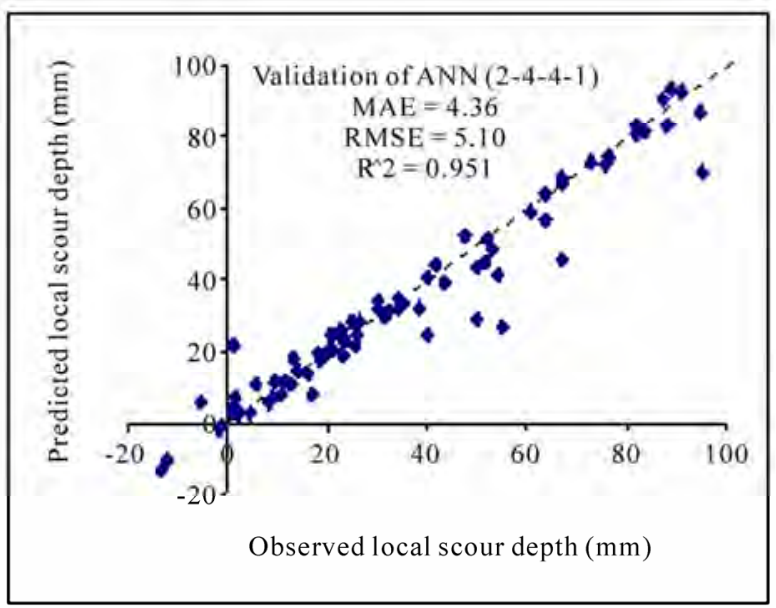

(a)

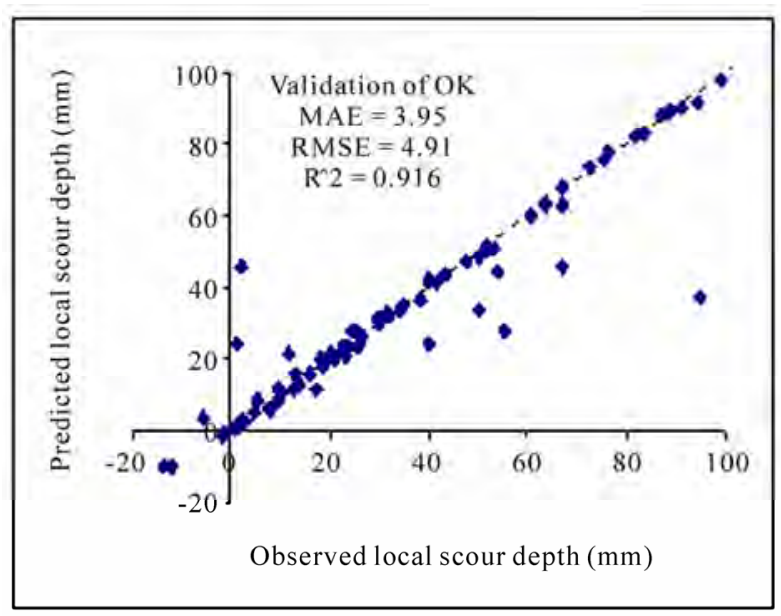

(c)

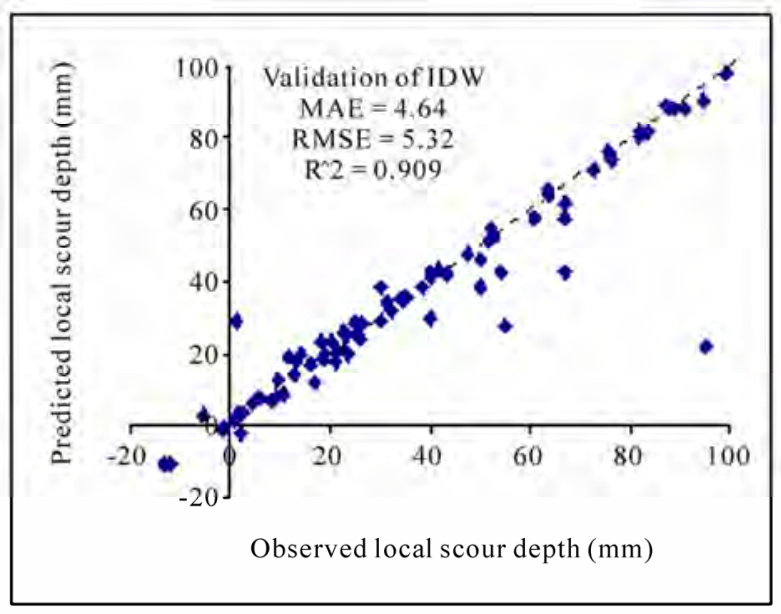

(e)

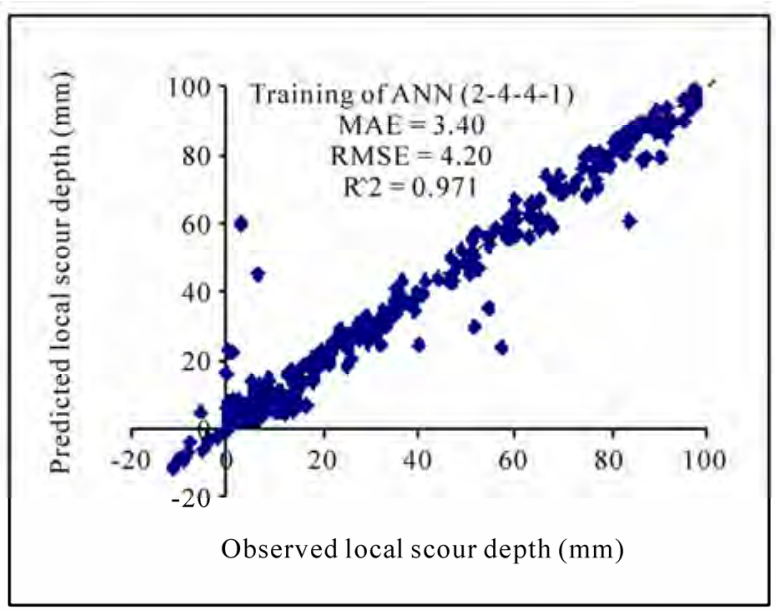

(b)

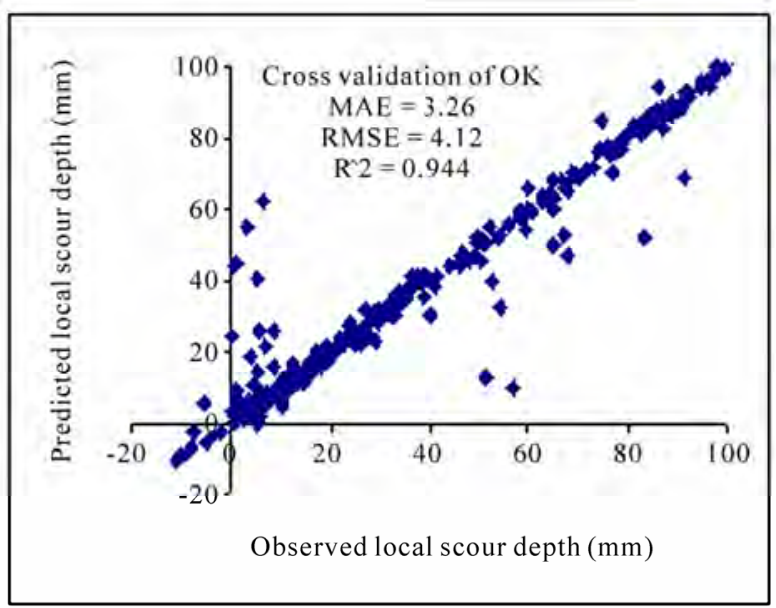

(d)

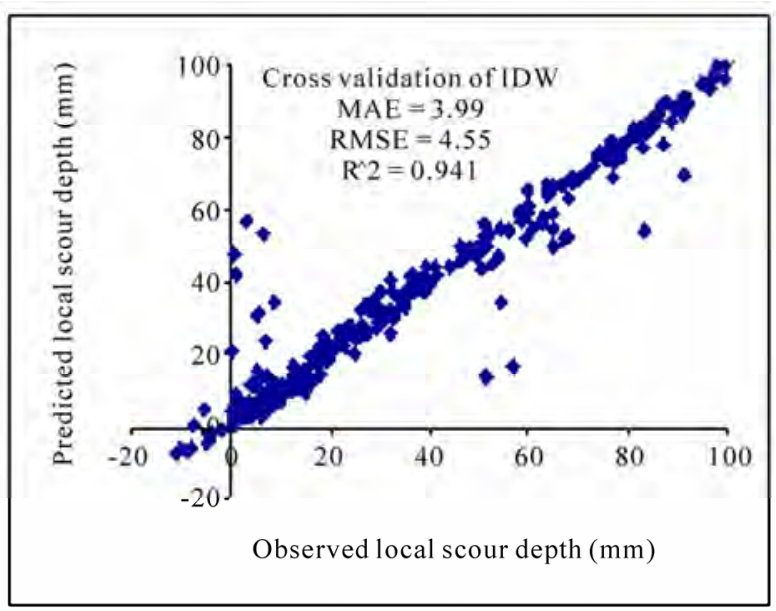

(f)

Figure 11. Performance of ANN, OK and IDW for the fourth test case: (a) ANN Validation; (b) ANN Training; (c) OK Validation; (d) OK Cross Validation; (e) IDW Validation; (f) IDW Cross Validation. 

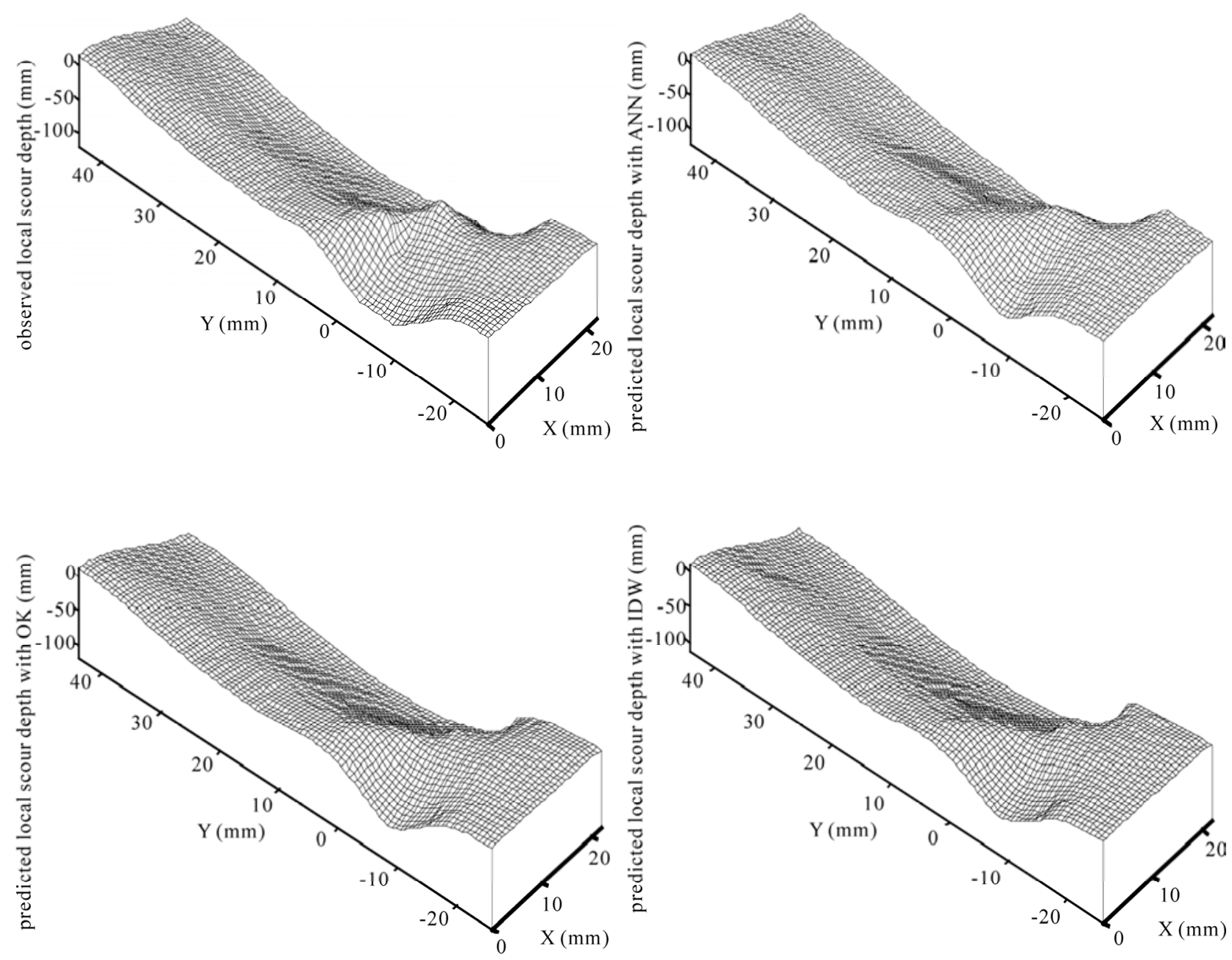

Figure 12. Interpolated maps of observed data, ANN, OK and IDW test for fourth test case.

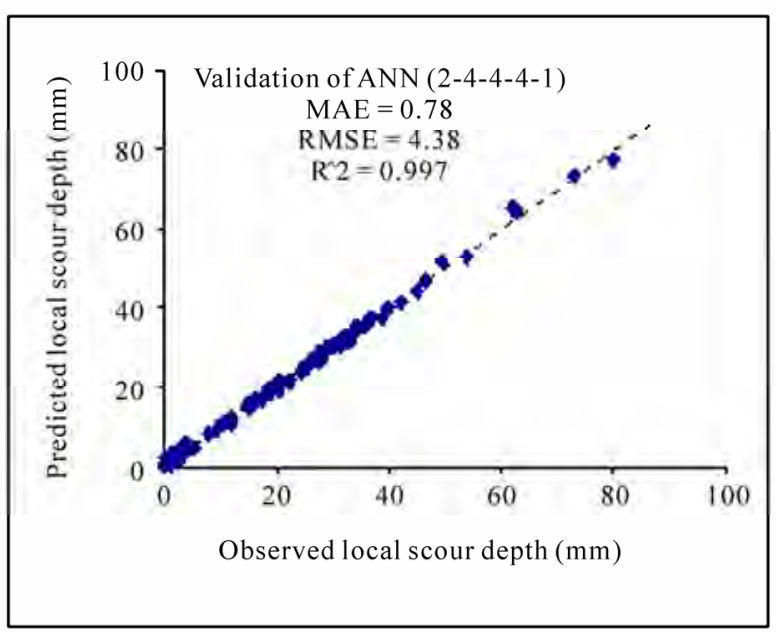

(a)

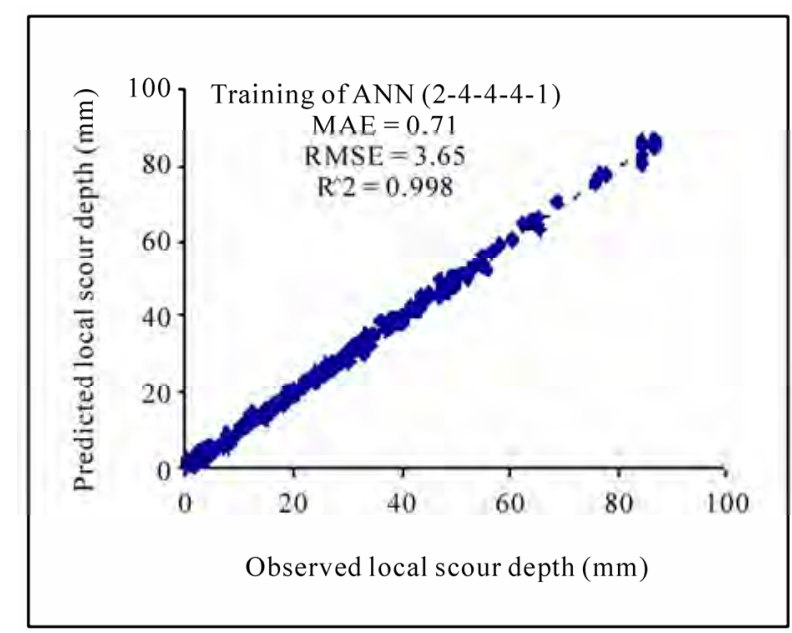

(b) 


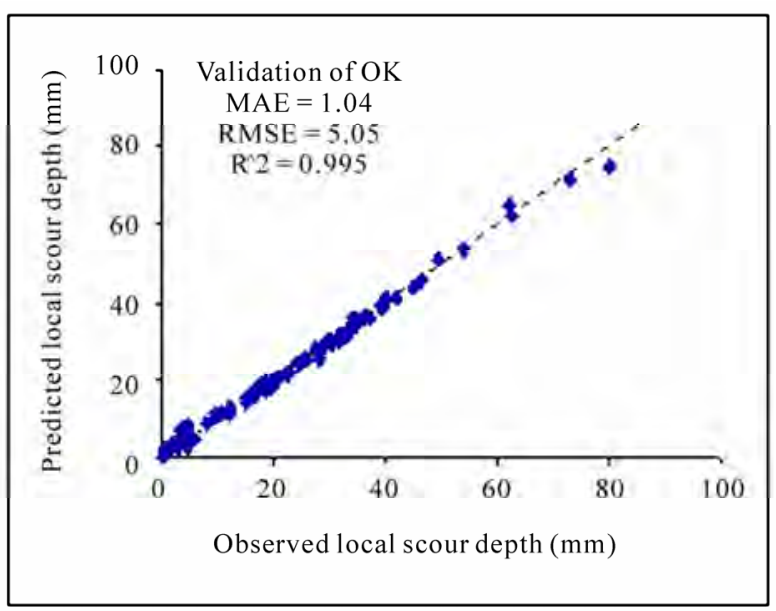

(c)

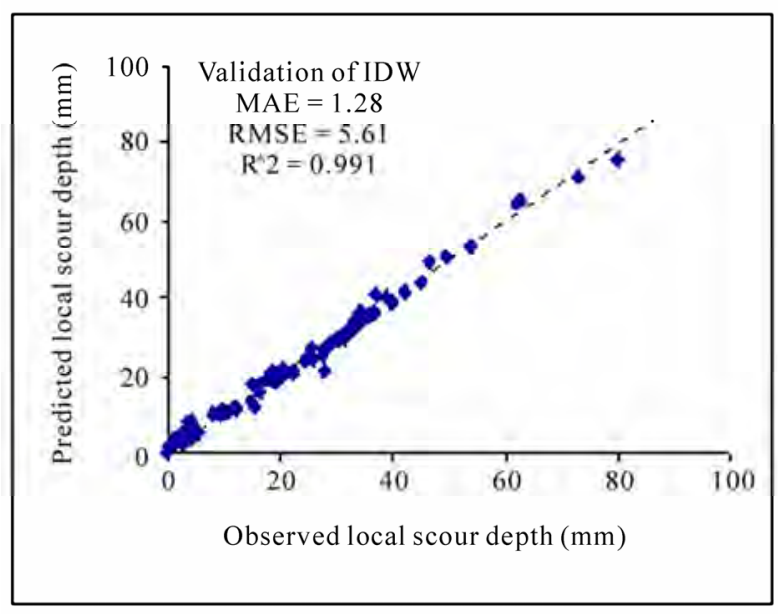

(e)

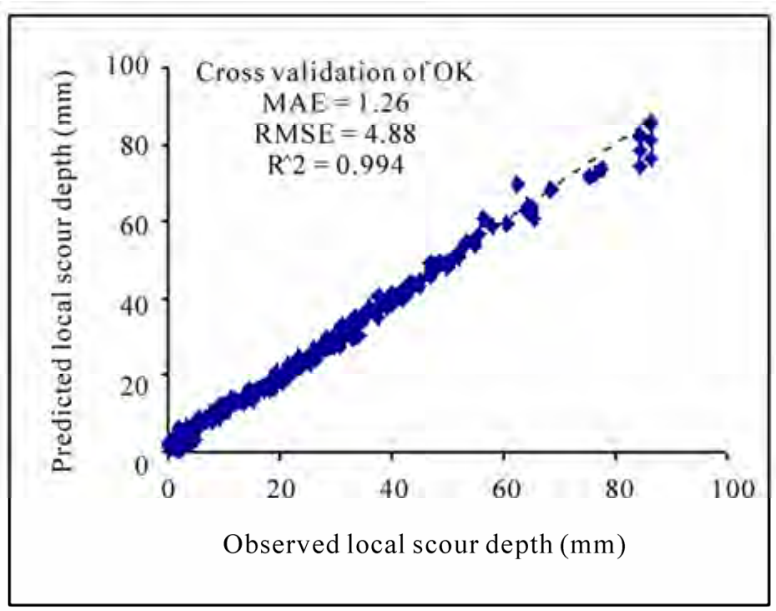

(d)

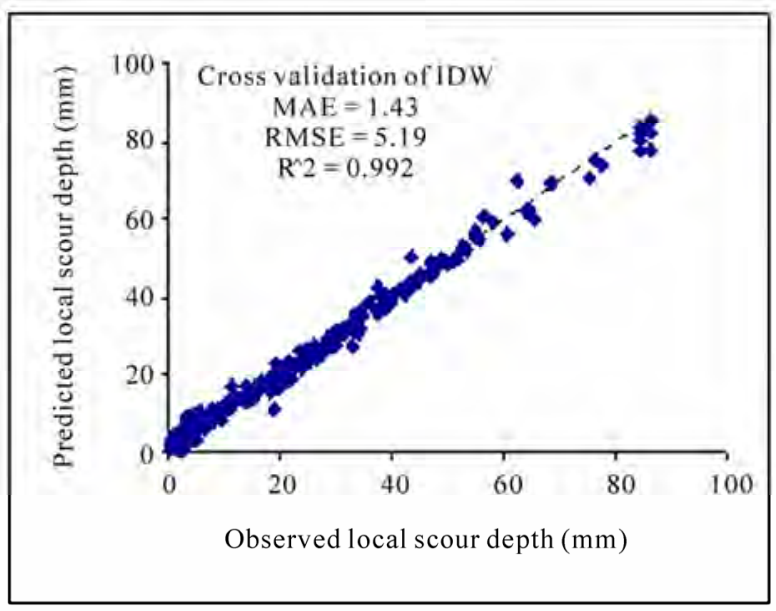

(f)

Figure 13. Performance of ANN, OK and IDW for the fifth test case: (a) ANN Validation; (b) ANN Training; (c) OK Validation; (d) OK Cross Validation; (e) IDW Validation; (f) IDW Cross Validation.
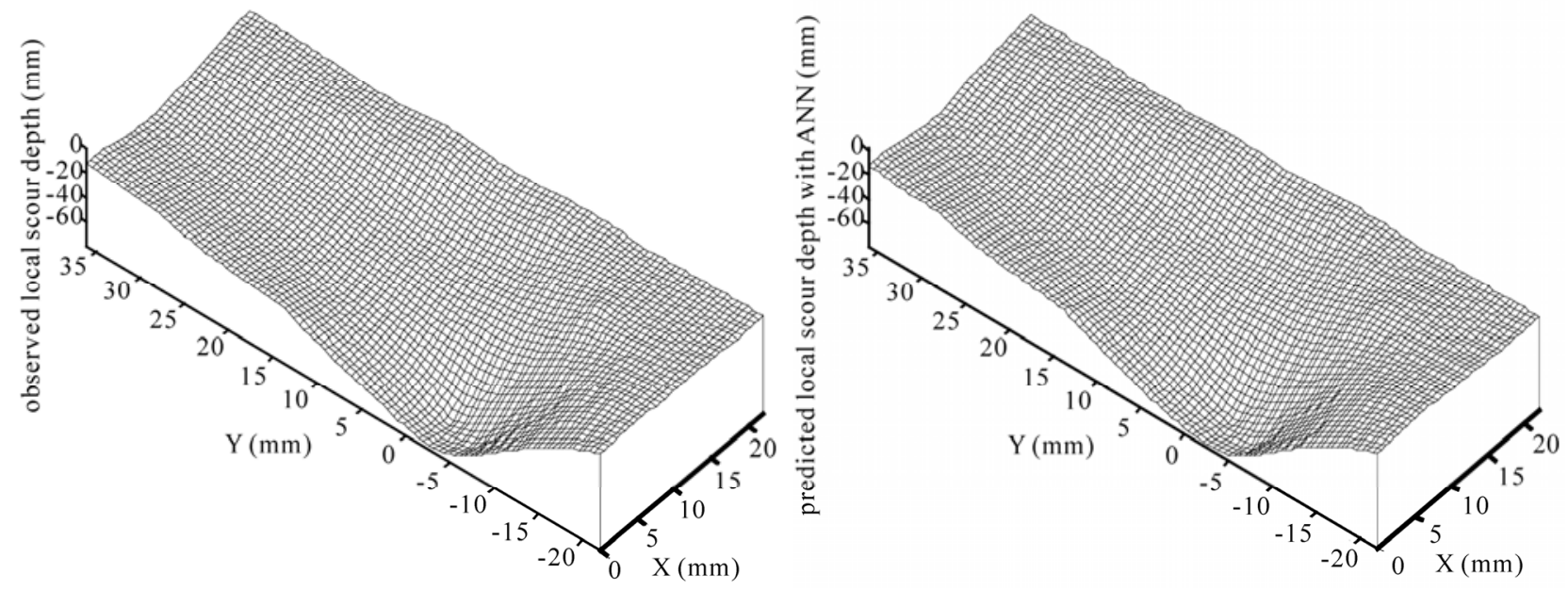

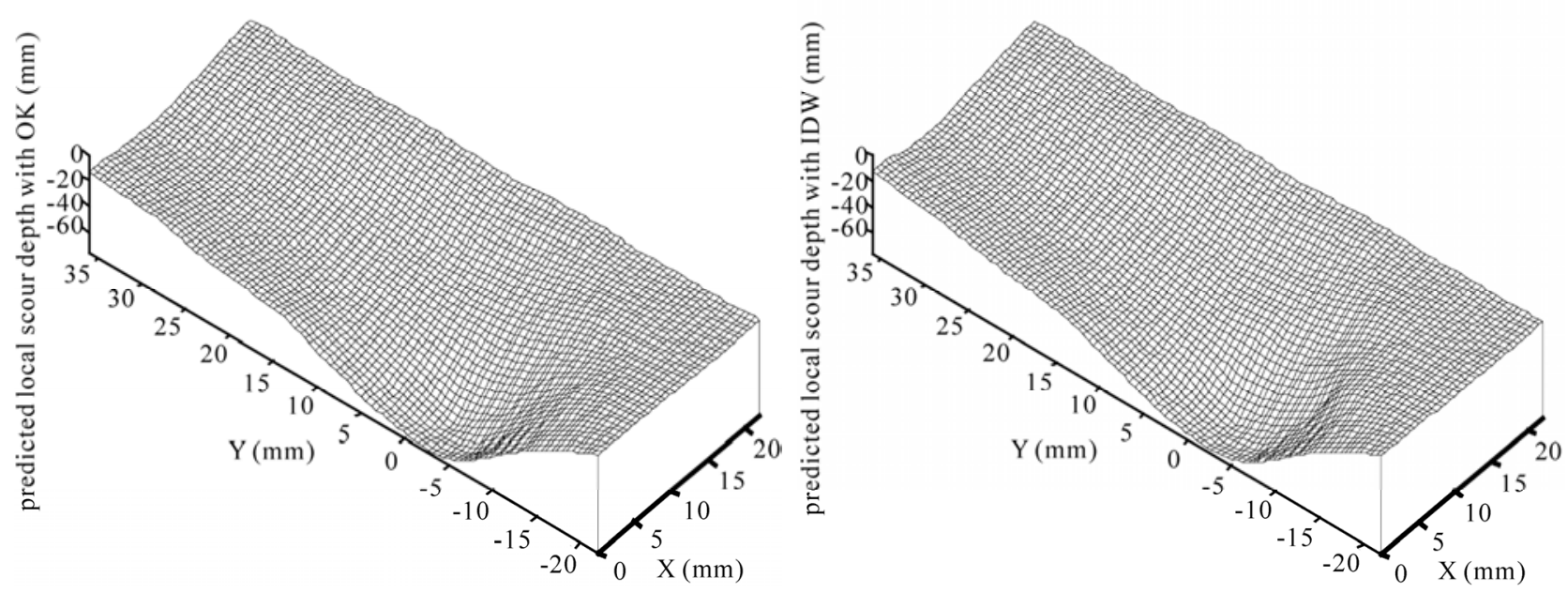

Figure 14. Interpolated maps of observed data, ANN, OK and IDW test for fifth test case.

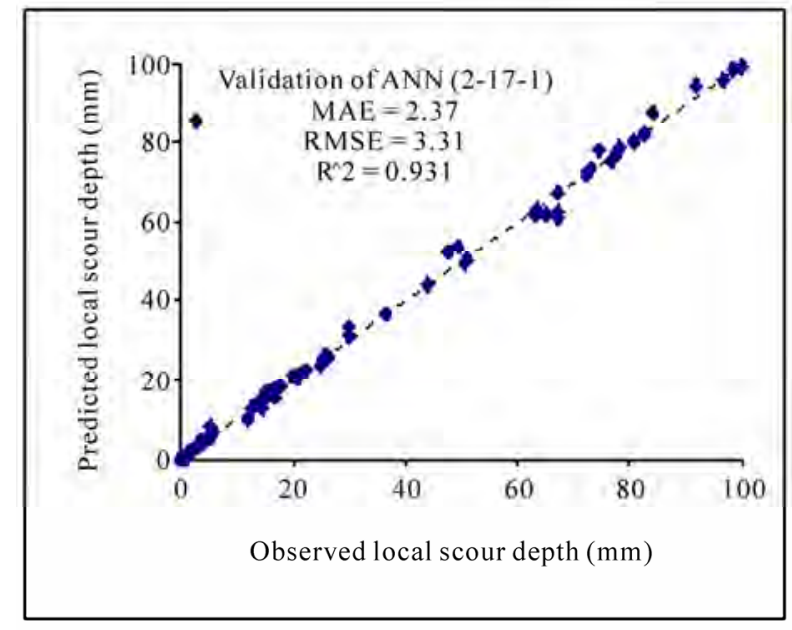

(a)

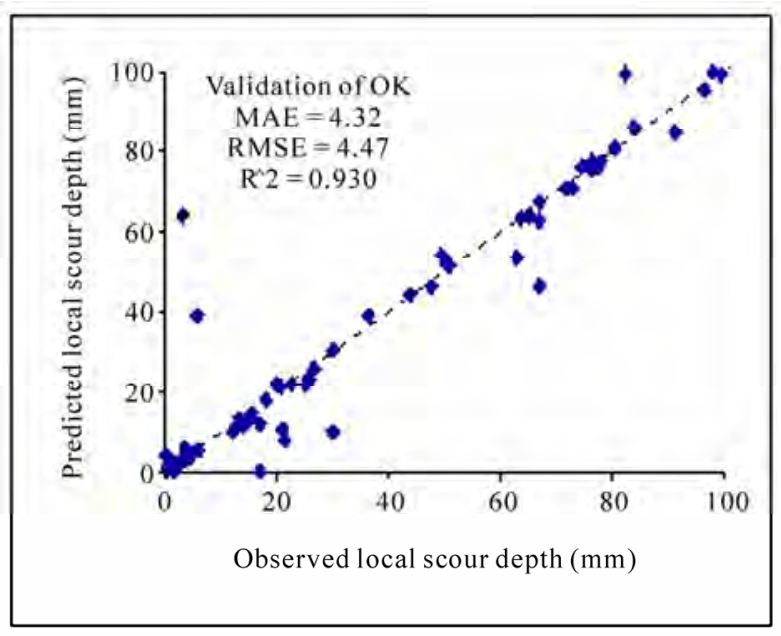

(c)

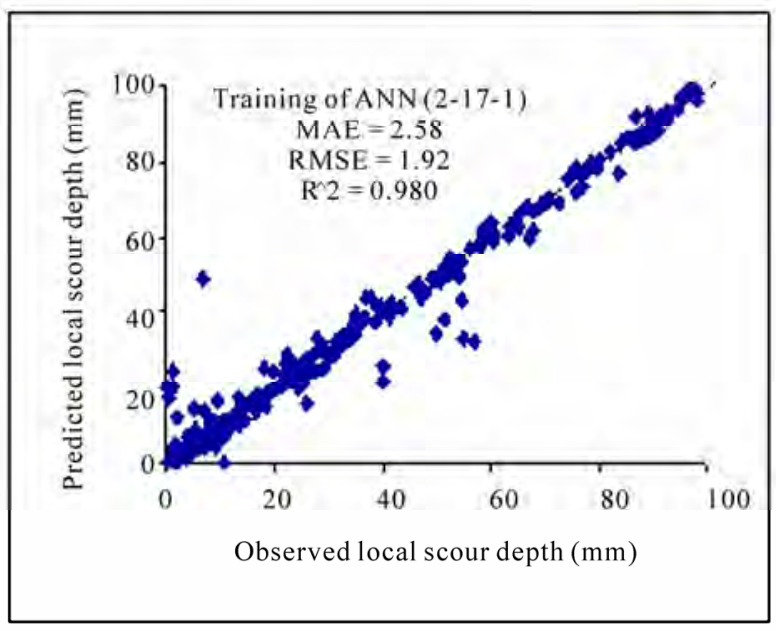

(b)

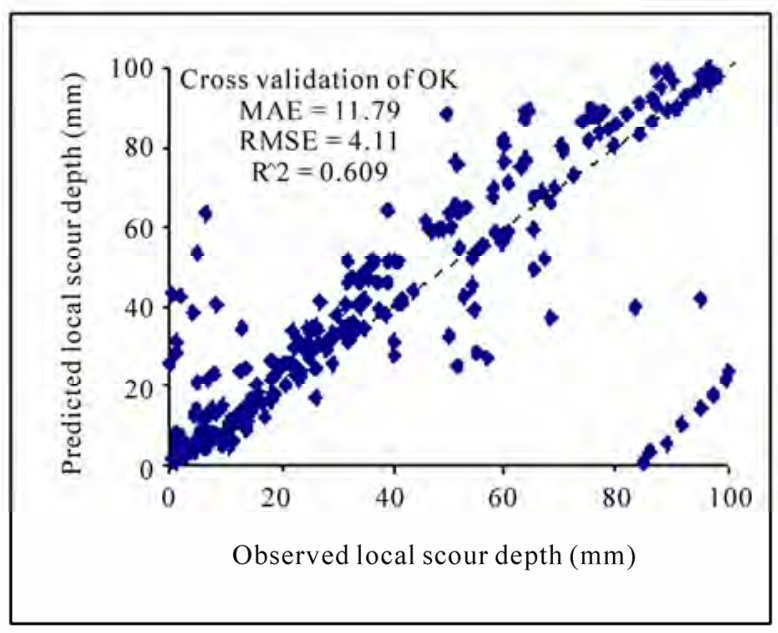

(d) 


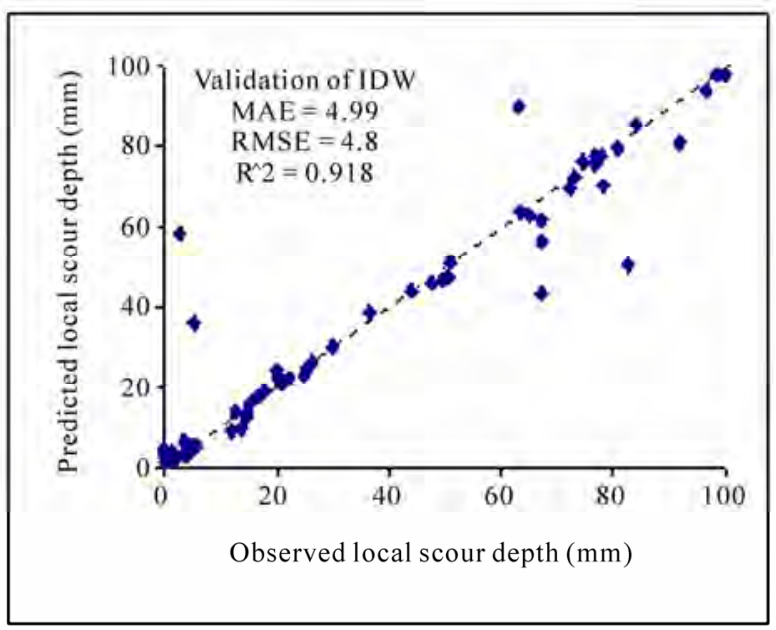

(e)

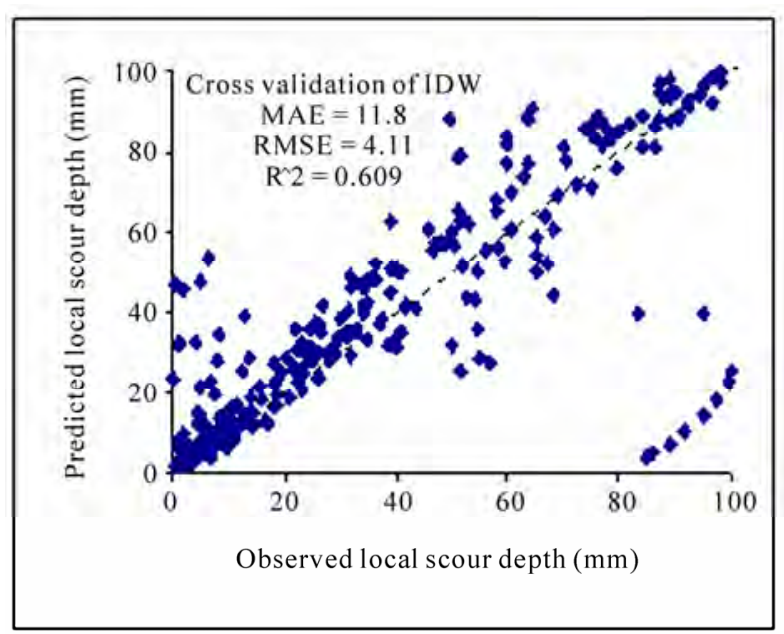

(f)

Figure 15. Performance of ANN, OK and IDW for the sixth test case: (a) ANN Validation; (b) ANN Training; (c) OK Validation; (d) OK Cross Validation; (e) IDW Validation; (f) IDW Cross Validation.
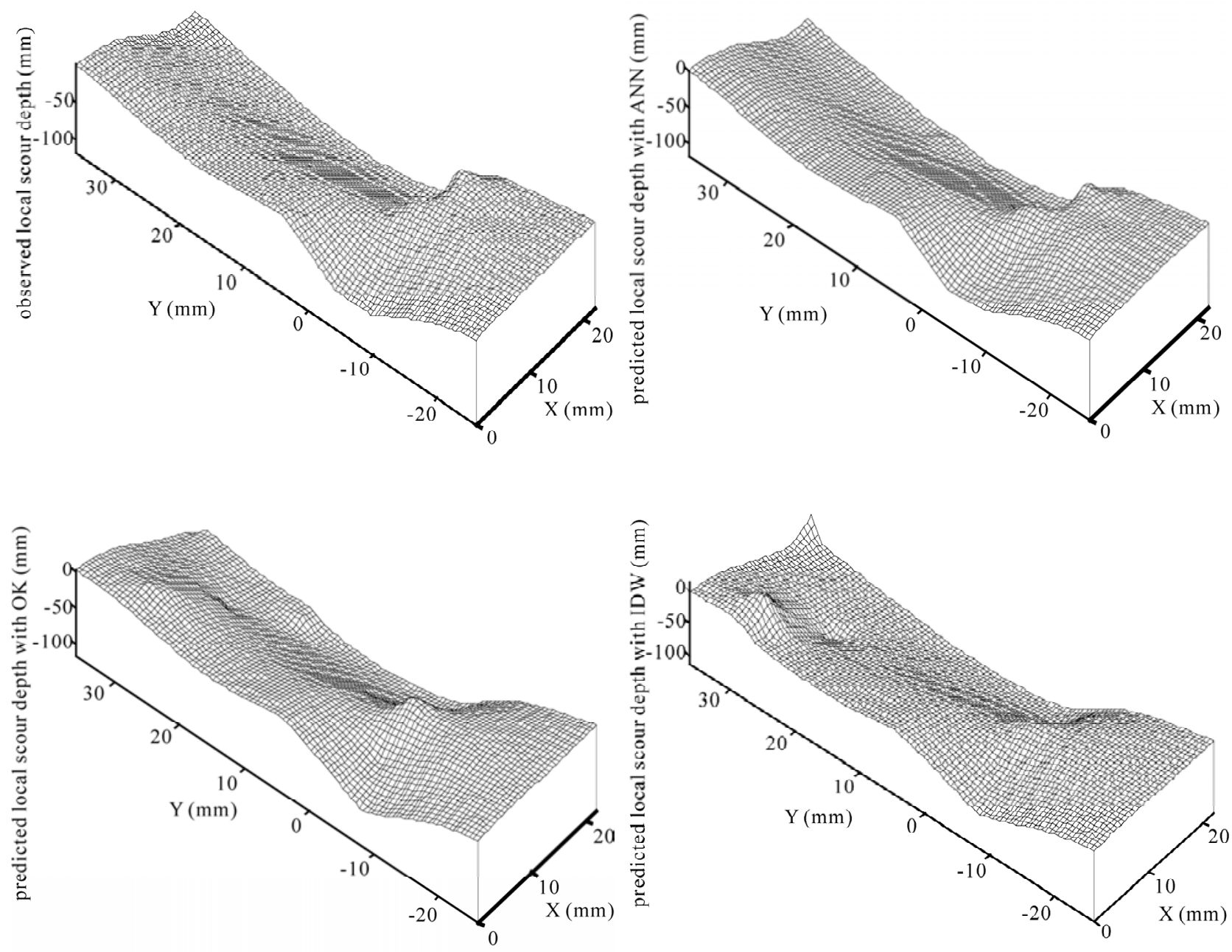

Figure 16. Interpolated maps of observed data, ANN, OK and IDW test for sixth test case. 


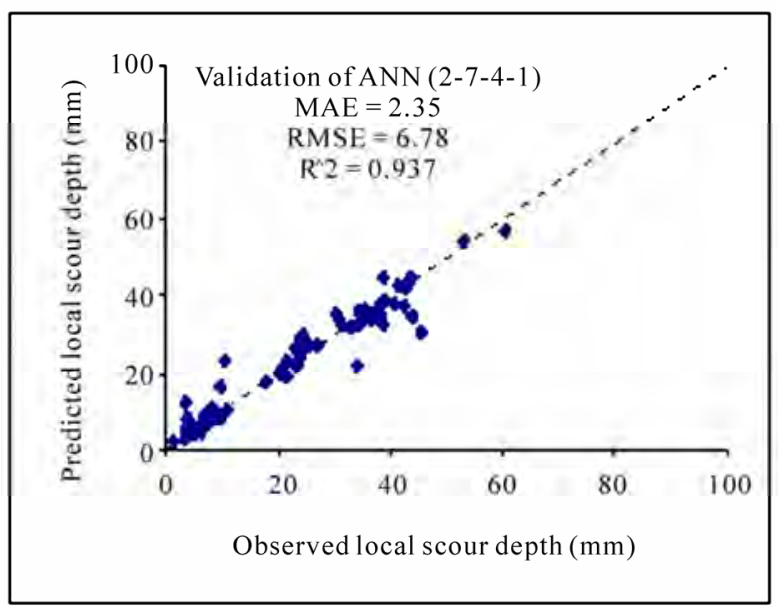

(a)

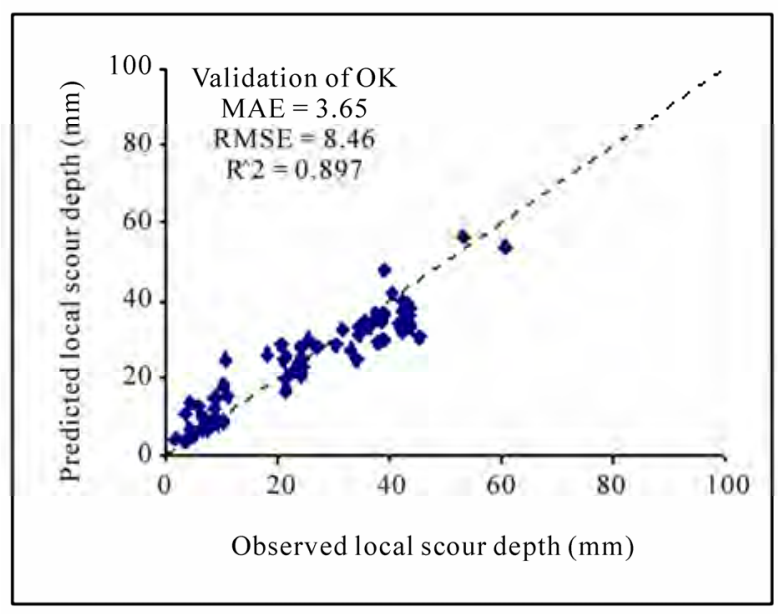

(c)

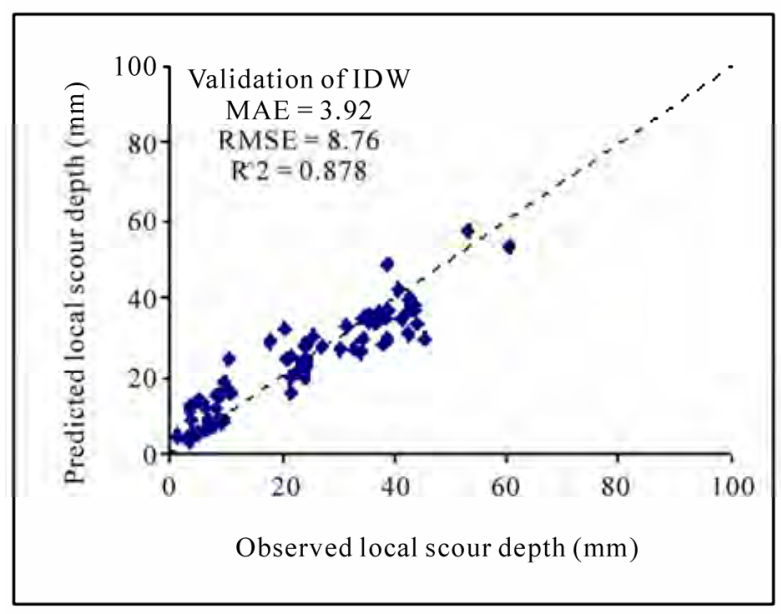

(e)

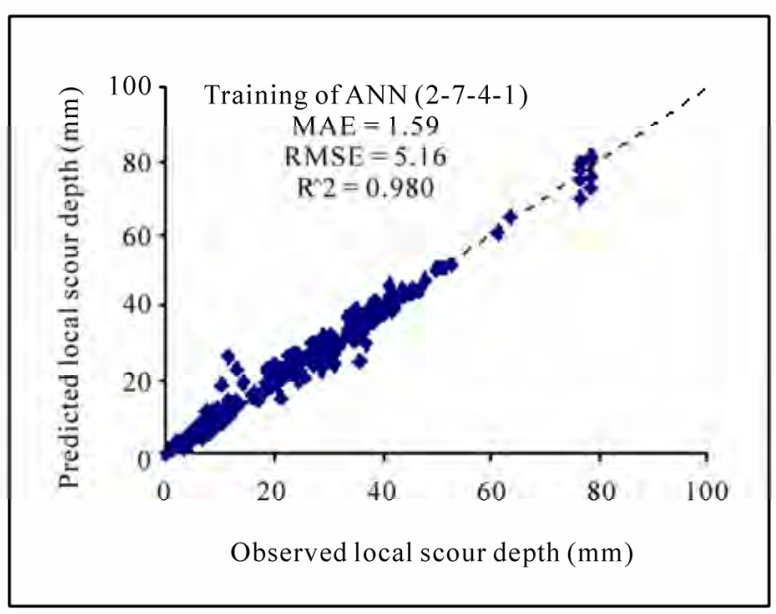

(b)

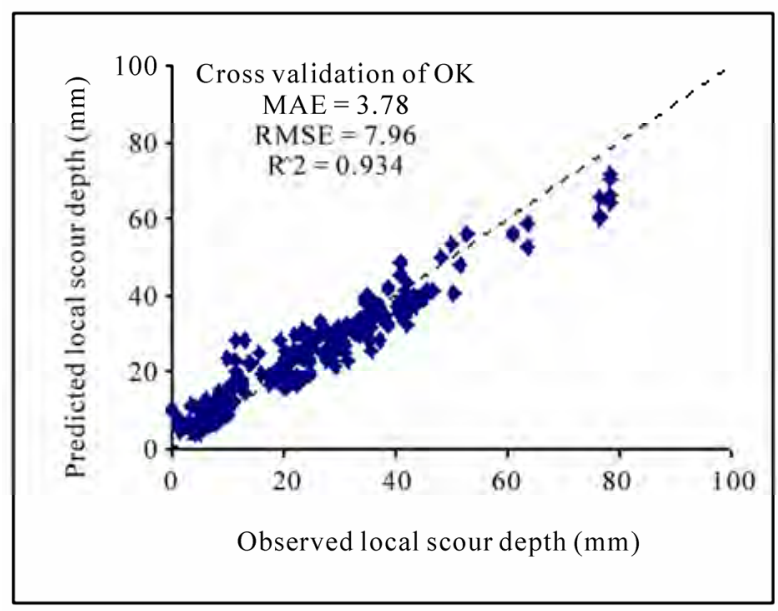

(d)

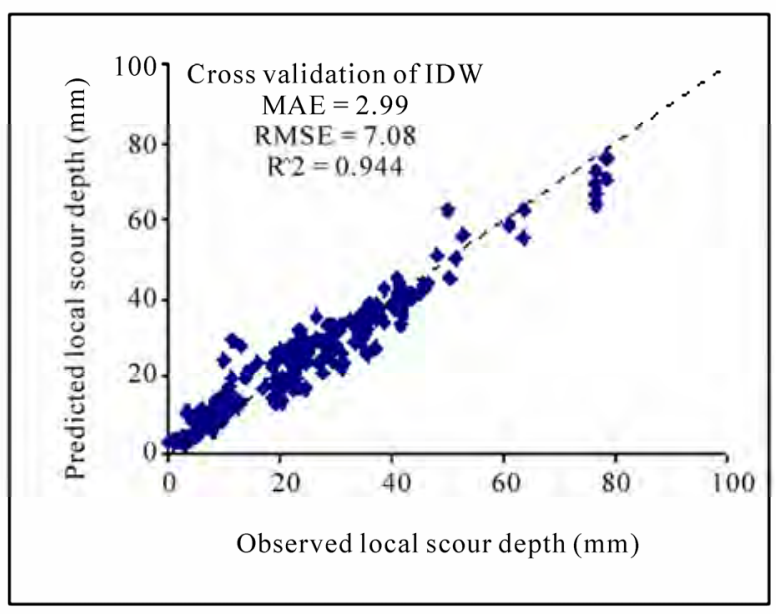

(f)

Figure 17. Performance of ANN, OK and IDW for the seventh test case: (a) ANN Validation; (b) ANN Training; (c) OK Validation; (d) OK Cross Validation; (e) IDW Validation; (f) IDW Cross Validation. 

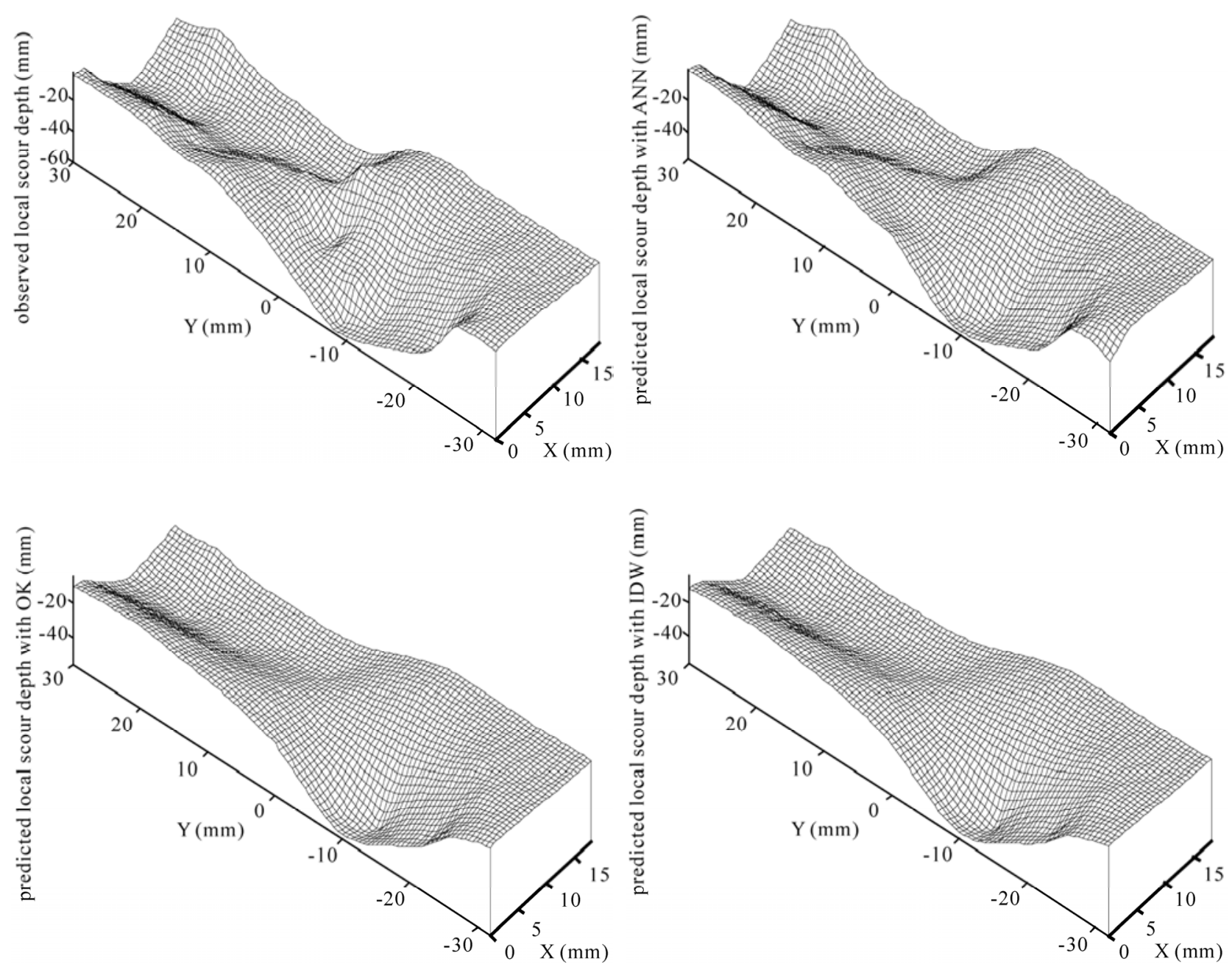

Figure 18. Interpolated maps of observed data, ANN, OK and IDW test for seventh test case.

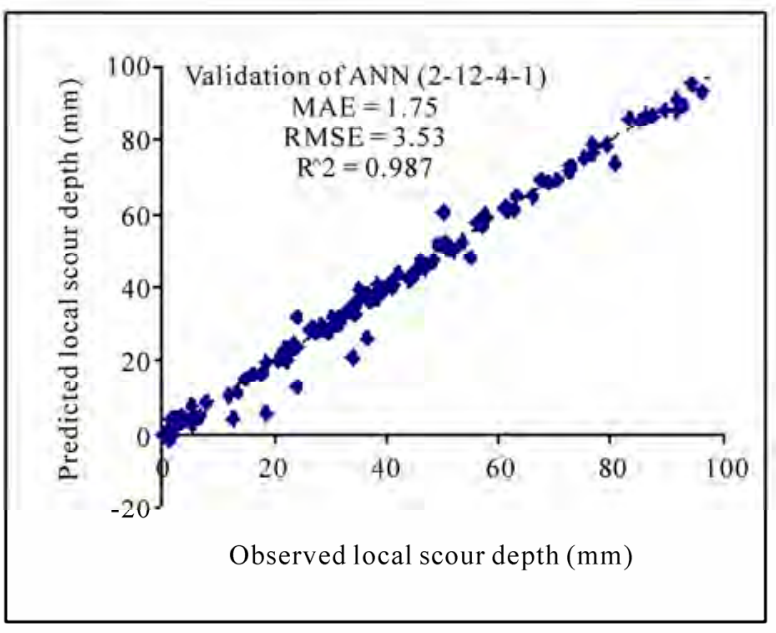

(a)

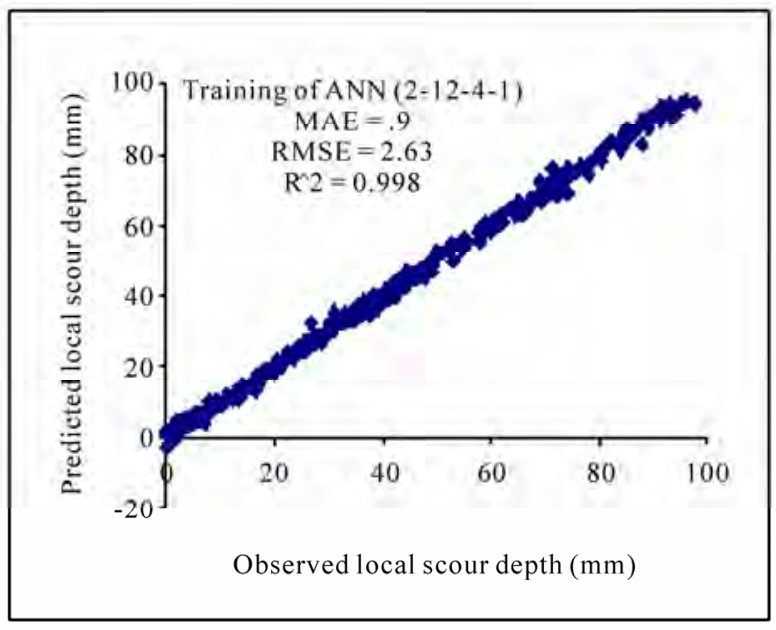

(b) 


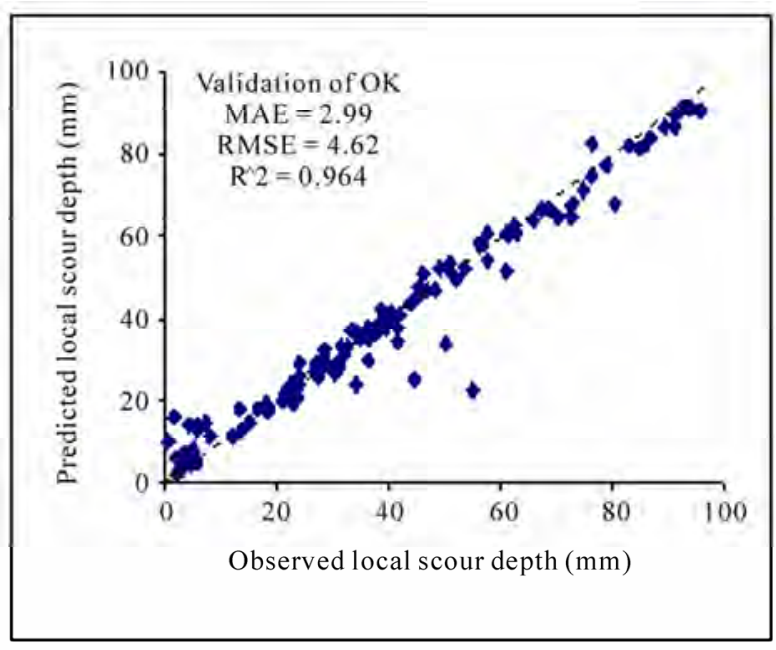

(c)

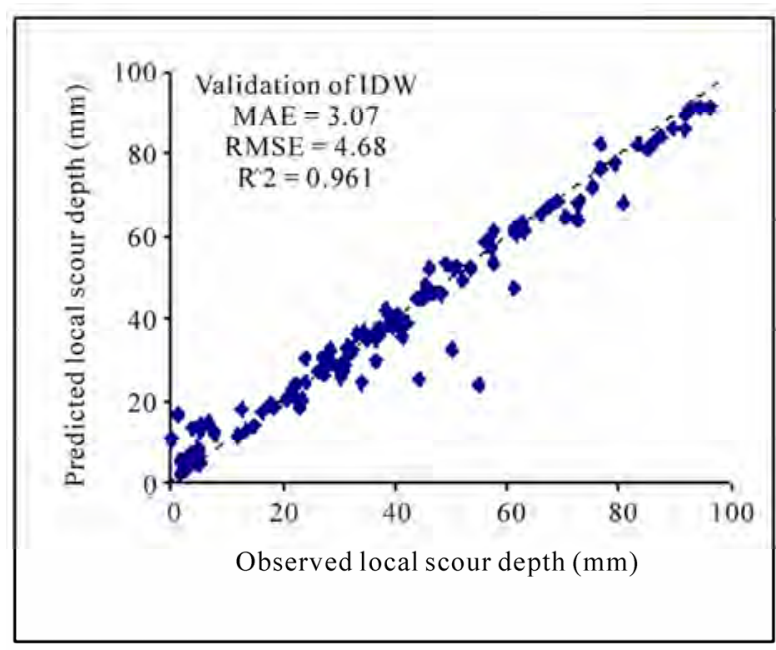

(e)

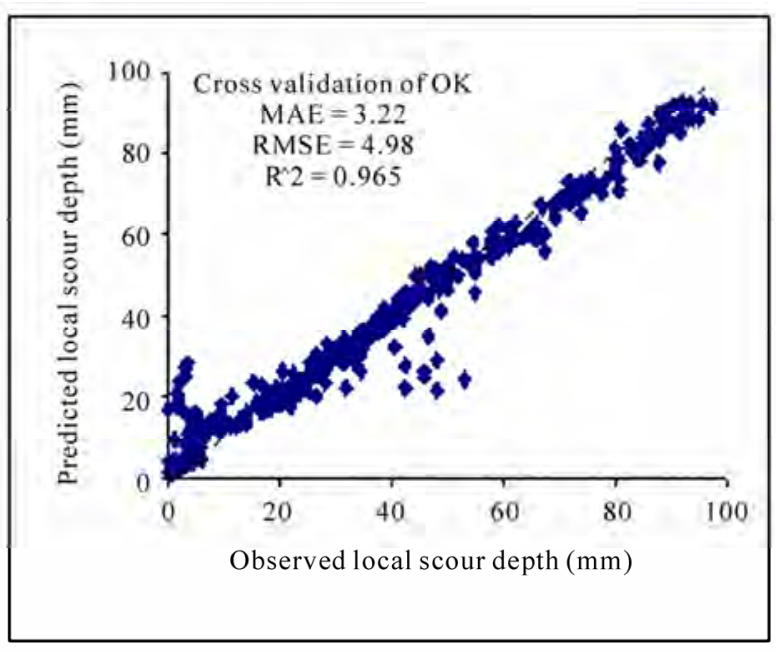

(d)

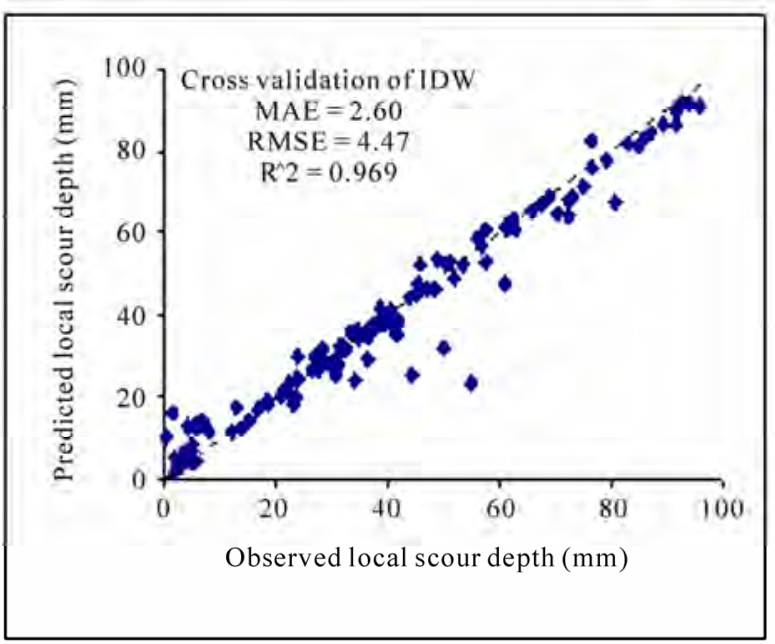

(f)

Figure 19. Performance of ANN, OK and IDW for the eighth test case: (a) ANN Validation; (b) ANN Training; (c) OK Validation; (d) OK Cross Validation; (e) IDW Validation; (f) IDW Cross Validation.

however the diameter of bed sill was equal to 1.2 times the channel width.

From ANN prediction, the optimal architecture was determined by varying the number of hidden neurons (from 1 to 20), and the best structure was selected. It was found that best structure has only one hidden layer and its architecture has the configuration of 2-17-1.

Figure 15 shows training and validation results, respectively. Again, the ANN model performs much better in training and validation. In OK and IDW the accuracy of training is less than validation, but OK showed the best results after ANN. An interpolated map of ANN (Figure 16) conforms to the interpolated map of observed local scour depth but the OK and IDW interpo- lated maps are not matched to the observed interpolated map.

\subsection{Seventh Test Case}

This seventh test case was similar to the third case, however the diameter of bed sill was equal to 1.2 times the flume width.

From ANN prediction the best structure was selected. It was found that the most accurate results involved use of configuration 2-7-4-1.

Figure 17 depict training and validation results separately for ANN, OK and IDW, respectively, for the seventh data set. When these methods are compared, it was shown that ANN had the best accuracy and IDW had a 

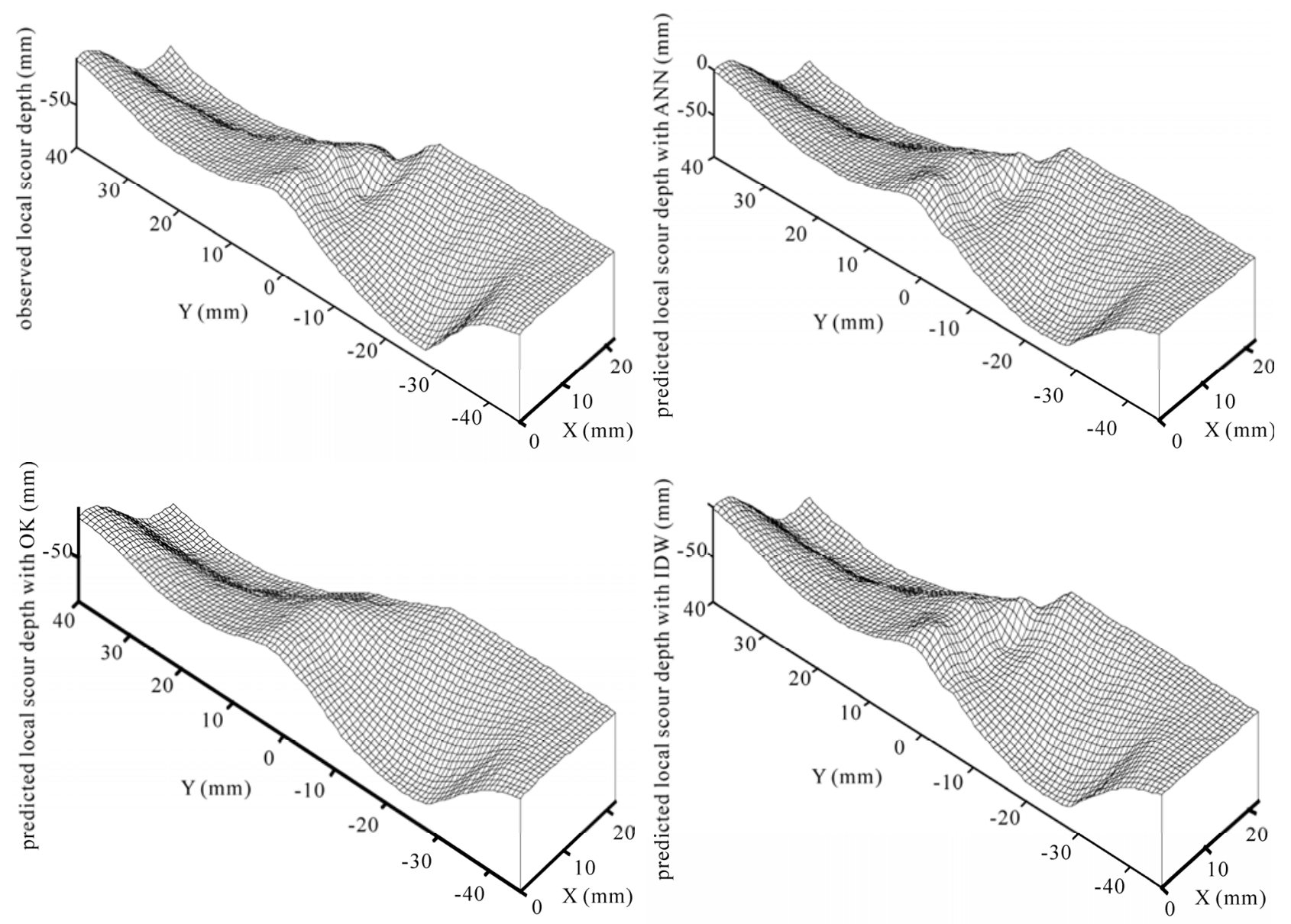

Figure 20. Interpolated maps of observed data, ANN, OK and IDW test for eighth test case.

low accuracy. Comparisons between these three interpolated maps show that the interpolated map of ANN is very similar to the interpolated map of observed local scour depth (see Figure 18).

\subsection{Eighth Test Case}

In the eighth test case, the bed sill was set in the flow direction with a distance of $25 \mathrm{~cm}$ between the bridge pier and bed sill. From ANN prediction the best structure was selected. It was found that the most accurate results involved the use of a configuration 2-12-4-1. In the estimate from this test case, like the last seven estimates, ANN has better results when compared with the other methods (Figure 19) and the difference in accuracy between OK and IDW isn't significant, as confirmed by the interpolated maps (Figure 20).

\section{Appropriate Methods for Prediction of Local Scour Depth}

In order to identify the most accurate of the three pre- sented methods, Table $\mathbf{1}$ represents the results of the research for all conditions. For all conditions, the ANN has the best accuracy in training and validation. ANN performance shows significant preciseness under every condition for the prediction of local scour depth. Only in the fifth test case, the difference in accuracy was very close for all methods. Performance of OK reveals good accuracy, but it has lower precision when compared with the ANN performance. In OK and IDW, accuracy of training is almost the same but $\mathrm{OK}$ has better precision in validation performance. Consequently, IDW shows lower performance over all conditions.

\section{Conclusions}

This paper outlines the application of artificial neural network (ANN), namely the multi-layer perceptron, the ordinary kriging $(\mathrm{OK})$ and the inverse distance weighting (IDW) models in the estimation of local scour depth around bridge piers where bed sills have been installed.

The results of this study showed that the ANN model 
gives more accurate local scour depth predictions than the existing methods. As such, it is recommended that the ANN model be used for local scour depth predictions instead of the kriging and inverse distance weighting models.

The ANN with two hidden layers was selected as the optimum network to predict local scour depth, whereas the network that includes one hidden layer and 17 hidden nodes within that layer was the best model to predict local scour depth as it is shown in the sixth test case with $\mathrm{D} / \mathrm{W}=1.2$ and $\mathrm{r}=5 \mathrm{~cm}$. Also three layers was found the best model to predict local scour depth for test case with no sill as it is shown in the fifth test case.

\section{REFERENCES}

[1] D. S. Jeng, S. M. Bateni and E. Lockett, "Neural Network Assessment for Scour Depth Around Bridge," Department of Civil Engineering, the University of Sydney, Sydney, NSW, Australia, Environmental Fluids/Wind Group, Research Report No R855, 2006.

[2] N. E Yankielun and L. Zabilansky, "Laboratory Investigation of Time-Domain Reflectometry System for Monitoring Bridge Scour,” Journal of Hydraulic Engineering, ASCE, Vol. 125, No. 12, 1999, pp. 1279-1284.

[3] P. A. Johnson, "Comparison of Pier-Scour Equations Using Field Data,” Journal of Hydraulic Engineering, ASCE, Vol. 121, No. 8, 1995, pp. 626-629.

[4] R. Trent, N. Gagarain and J. Rhodes, "Estimating Pier Scour with Artificial Neural Networks," Proceedings of ASCE Conference on Hydraulic Engineering, San Francisco, CA, 1993a, pp. 1043-1048.

[5] R. Trent, A. Molinas and N. Gagarain, “An Artificial Neural Networks for Computing Sediment Estimation of Scour Below Spillways Using Neural Networks," Proceedings of ASCE Conference on Hydraulic Engineering, San Francisco, CA, 1993b, pp. 1049-1054.
[6] S. Choi and S. Cheong, "Prediction of Local Scour around Bridge Piers Using Artificial Neural Networks," Journal of the American Water Resources Association, Vol. 42, No 2, 2006, pp. 487-494.

[7] J. B. Butcher, "Co-kriging to Incorporate Screening Data: Hudson River Sediment," Journal of the American Water Resources Association, Vol. 32, No. 2, 1996, pp. 349356.

[8] B. Biglary and T. W. Sturm, "Numerical Modeling of Flow around Bridge Abutments in Compound Channel," Journal of Hydraulic Engineering, ASCE, Vol. 124, 1998, pp. 156-164.

[9] S. L. Liriano and R. A. Day, "Prediction of Scour Depth at Culvert Outlets Using Neural Networks,” Journal of Hydroinformatics, Vol. 3, 2001, pp. 231-238.

[10] A. R. Kambekar and M. C. Deo, "Estimation of Group Pile Scour Using Neural Networks," Applied Ocean Research, Vol. 25, No. 4, 2003, pp. 225-234.

[11] S. M. Bateni, S. M. Borghei and D. S. Jeng, "Neural Network and Neuro-Fuzzy Assessments for Scour Depth around Bridge Piers," Engineering Applications of Artificial Intelligence, Vol. 20, No. 3, 2007a, pp. 401-414.

[12] T. L. Lee, D. S. Jeng, G. H. Zhang and I. H. Hong, "Neural Network Modeling for Estimation of Scour Depth around Bridge Piers,” Journal of Hydrodynamic, Vol. 19, No. 3, 2007, pp. 378-386.

[13] S. M. Betani, D. S. Jeng and B. W. Melville, "Bayesian Neural Networks for Prediction of Equilibrium and Time-Dependent Scour Depth around Bridge Piers,” Advances in Engineering Software, Vol. 38, No. 2, 2007b, pp. 102-111.

[14] Mathworks, "Neural Network Toolbox for Use with MATHLAB,” User's Guide, the MathWorks, Inc., Natick, MA, 2006, pp. 2-1 to 3-36.

[15] Golden Software User’s guide, "Surfer Contouring and 3D Surface Mapping for Scientists and Engineers," 8th Edition, Golden Software, Inc., Golden, CO, 2002. 